This item was submitted to Loughborough's Research Repository by the author.

Items in Figshare are protected by copyright, with all rights reserved, unless otherwise indicated.

\title{
Feedback messaging, thermal comfort and usage of office-based personal comfort systems
}

PLEASE CITE THE PUBLISHED VERSION

https://doi.org/10.1016/j.enbuild.2019.109514

\section{PUBLISHER}

Elsevier BV

VERSION

AM (Accepted Manuscript)

\section{PUBLISHER STATEMENT}

This paper was accepted for publication in the journal Energy and Buildings and the definitive published version is available at https://doi.org/10.1016/j.enbuild.2019.109514.

\section{LICENCE}

CC BY-NC-ND 4.0

\section{REPOSITORY RECORD}

Li, Ziqiao, Dennis Loveday, and Peter Demian. 2019. "Feedback Messaging, Thermal Comfort and Usage of Office-based Personal Comfort Systems”. Loughborough University. https://hdl.handle.net/2134/11877993.v1. 


\title{
Feedback messaging, thermal comfort and usage of office-based personal comfort systems
}

\author{
Ziqiao Li a, ", Dennis Loveday a, Peter Demian a \\ a School of Architecture, Building \& Civil Engineering, Loughborough University, Loughborough, LE11 \\ 3TU, UK \\ *Corresponding author: Ziqiao Li (Z.Li2@lboro.ac.uk)
}

\begin{abstract}
Psychological processes are involved in human thermal comfort evaluation, and play a role in people's judgement of their thermal environment. Could these processes be beneficially managed in some way? This paper reports what is believed to be the first investigation of whether messaging, in the form of energy feedback and social normative information, can affect human subjective thermal comfort-related evaluations. Work was conducted in a controlled environmental room, the context being that of a multi-occupant office with messaging being delivered to individuals via a computer screen on each desk. Investigations were conducted for a range of warm office conditions $\left(24.5^{\circ} \mathrm{C}, 27^{\circ} \mathrm{C}, 29.5^{\circ} \mathrm{C}\right.$, as might be encountered in summertime). Experimental sessions of two hours' duration were undertaken for: no messaging; messaging appearing at the second hour; messaging present at first hour then removed at second hour. A total of 62 subjects ( 23 female and 39 male) took part, with all (except one) of the thermal conditions that involved messaging being experienced by 9 participants.
\end{abstract}

The appearance of energy feedback and social normative messaging was found to have a statistically-significant effect on reported thermal sensations, reported thermal comfort and reported intended desk fan usage, these being observed at the higher end of the temperature range, but had no effect on other subjective evaluations. Presence, then removal, of messaging showed no significant effects, as did an effective 'control group' comparison. Whilst effects were observed on certain subjective thermal evaluations at the higher temperatures, these were at the 95\% confidence level, and it is recommended that a larger scale study be undertaken to confirm, or otherwise, these observations.

The study offers a method that can be followed for future investigations under controlled conditions, and serves to design further, larger-scale, experiments, to investigate actual usage of personal comfort systems and the role of messaging in this context. Implications of any 'intervention-type' influences (of which 'messaging' could be an example) on subjective evaluations, if confirmed, may open a new way to help manage human thermal comfort and energy use in offices or similar environments, but this will require further careful consideration, particularly from the perspective of human health and well-being, prior to any deployment in practice.

Keywords: 
Thermal comfort; Energy Feedback; Social norms; Occupant behaviour; Thermal adaptation; Feedback messaging

\section{Introduction}

The long-standing definition of thermal comfort is 'that condition of mind that expresses satisfaction with the thermal environment' (ASHRAE, 2013). Thermal comfort is a subjective feeling involving the processes of both physiological and psychological evaluation. From the viewpoint of heat transfer, Fanger (1970) proposed a heat balance equation to describe the process of human heat production and heat release to the surrounding environment. This was followed by its relation (also developed by Fanger, 1970) to the actual thermal sensations reported by a large group of people for various combinations of activity, clothing and environmental variables, and expressed as the Predicted Mean Vote (PMV). However, since its inception, numerous researchers (including De Dear et al., 1991; Croome et al., 1992; Oseland, 1995; Parsons, 2002) have reported instances where discrepancies exist between comfort predictions based on Fanger's PMV approach and the actual thermal comfort reported in practice.

Considering this discrepancy, researchers (including Martinez et al., 2000; Brager et al., 2004; Huizenga et al., 2004; Yao et al., 2007; Nicol et al., 2012) suggested that occupants in actual buildings would experience a thermal adaptive and acclimation process. De Dear et al. (1998) remarked that this discrepancy is a result of contextual factors and thermal experiences, such as building ventilation types, perceived control and past thermal experiences. This phenomenon was summarised as thermal adaptation, being comprised of the following three components: physiological adaptation; behavioural adaptation; and psychological adaptation.

Psychological adaptation refers to the changes in people's perceptions of, and reactions to, sensory information based on their previous thermal experience and expectation (Brager and de Dear, 1998; Yao et al., 2009). Many studies have demonstrated the existence of psychological adaptation from various aspects, including contextual factors (Rohles, 2007; Deuble and de Dear, 2012; Toftum et al., 2018), cultural background and past thermal experience (Schweiker and Shukuya, 2009), and perceived level of control (Brager et al., 2004; Schweiker and Wagner, 2016).

Specifically, Rohles (2007) found that participants felt warmer by simply telling them that the temperature was now increased. Deuble and de Dear (2012) reported a positive relation between occupant satisfaction levels and their environmental beliefs, and found that occupants in "green" buildings were more accepting of the less-thanideal conditions, compared to those in normal buildings. Toftum et al. (2018) reported that thermal sensation could be changed by different colour temperatures of LED lighting. In addition, Schweiker and Shukuya (2009) reported that the frequency of 
using air-conditioning systems was significantly influenced by participants' cultural background and past thermal experience.

Occupants' evaluation of thermal comfort and satisfaction can also be changed by their perceived control level. Bordass et al. (1994) explained that people are more accepting of variations that come from a known source, while Brager et al. (2004) stated that occupants with a greater degree of thermal control could have a relaxation of expectation and a greater tolerance of temperature. Additionally, studies investigated the link between thermal comfort and perceived control from different perspectives, including personal control over environments (Clausen and Wyon, 2008; Lee and Brand, 2010; Luo et al., 2014), thermal comfort feedback (Feldmeier and Paradiso, 2010; Erickson et al., 2009; Hang-yat and Wang, 2013; Lam et al., 2014) and shared occupied space (Schweiker, 2016). Some of these studies also observed a reduced HVAC system energy consumption by providing occupants with a higher level of perceived control.

All this evidence implies that psychological processes are involved in human thermal comfort evaluation, and play a role in people's evaluation of their thermal environment. The question then arises as to whether specific types of 'messages', for which we shall use the term 'feedback messaging', might also influence people's thermal evaluation of their environment. For this study, we are particularly interested in two types of messages - energy feedback and social norms.

\subsection{Energy Feedback}

Energy feedback can be considered as a means to deliver to occupants information and timely insights (Ehrhardt-Martinez et al., 2010) so as to motivate, or even manipulate, them into adopting environmental concerns and energy-saving behaviours. Fischer (2008) explained why energy feedback could successfully influence occupants into adopting more eco-friendly behaviours. Firstly, feedback in the form of amount of energy consumed would be delivered to occupants, which directly raises their concerns about environmental issues. Secondly, such energy feedback motivates occupants to consider what to do and how, in order to reduce energy consumption. Then, with the benefits of cost saving and environmental protection, occupants might start to make decisions on whether it was worth their taking actions to change their energy-using behaviours.

In addition to Fischer's model (2008) (after Matthies, 2005), many experimental and field studies have been conducted, and the potential of energy feedback to save energy has been reported for both the public building sector (Petersen et al., 2007; Carrico and Riemer, 2011; Balaji et al., 2013) and the residential building sector (Schleich et al., 2013; Houde et al., 2013; Gans et al., 2013; Martin and Rivers, 2015). However, some studies reported that the approach of energy feedback alone was insufficient for reducing energy consumption (Delmas et al., 2013; Jain et al., 2013; Gulbinas and Taylor, 2014), especially for shared workplaces in office buildings 
(Dantsiou and Sunikka-Blank, 2015). Both Dantsiou and Sunikka-Blank (2015) and Karjalainen and Koistinen (2007) suggested that the reason could be occupants' reduced motivation, together with less control access, in shared workspaces, as well as complex HVAC systems in office buildings. Vellei et al. (2016) conducted an energy feedback study in student accommodation and found that real-time feedback helped and guided occupants to reduce room temperature and engage in adaptive actions that included clothing change and use of window opening controls. While energy feedback might raise people's pro-environmental concerns and lead to energy saving, no study to date has been found by the authors that directly identifies whether energy feedback affects reported human thermal comfort and related evaluations.

\subsection{Social norms}

Social norms are informal understandings that govern the behaviour of members of a society, and are normally divided into injunctive norms and descriptive norms. Generally, 'injunctive norms refer to the perceived approval or disapproval of behaviours by others, while descriptive norms indicate the perceived prevalence of others' actual behaviours' (Cialdini et al., 1990). Since people tend to behave like others who are considered to be similar, and are more willing to follow the norms of groups of which they feel they are members (Goldstein et al., 2008), social norms may have the potential to affect occupants' behaviours and thermal comfort evaluations, especially for shared workplaces. Recently, research interest in how social norms might affect people's thermal comfort has been raised by Shipworth et al. (2016), but the situation still remains unclear.

Although the direct effect of social norms on thermal comfort evaluation has not been investigated to date, their effects on energy saving, normally considered together with energy feedback, have been widely studied in the building sector. These studies illustrated their potential in reducing energy consumption when comparing one's own energy feedback with that of others, and also reported that energy feedback together with social normative information was more effective at saving energy than energy feedback alone (Peschiera et al., 2010; Foster et al., 2010; Handgraaf et al., 2013; Gulbinas and Taylor, 2014; Trinh, 2015). For example, Dolan and Metcalfe (2015) carried out an experiment with 569 households in London and found that the combination of energy feedback with social normative information resulted in $6 \%$ more energy saving than just energy feedback alone.

Although there is no direct evidence from the literature demonstrating that social norms affect subjective thermal evaluation, some studies have reported that people's thermal sensation could be influenced by social-related factors. Zhong and Leonardelli (2008) observed that occupants reported feeling cold and expressed a preference for warm food when they were experiencing social exclusion. Taufik et al. (2015) compared thermal sensations between one group self-perceived as eco-friendly with another group self-perceived as eco-unfriendly. Results revealed that a higher temperature was perceived by the 'eco-friendly' participants. 
Interest continues to grow in personal thermal comfort, delivered through individual systems that allow occupants in buildings to control their own local thermal environments (see for example Zhang et al., 2015; Shahzad et al., 2017). Such systems have been reported to lead to subjective thermal comfort improvement and enhanced energy-saving potential (Shahzad et al., 2018). Open-plan offices shared by a group of workers are very common and are designed to provide a flexible working environment that facilitates office workers' communication, social cohesiveness and productivity (Hedge, 1982). The combination of personal comfort (PC) systems and open-plan offices provides an ideal setting for applying messaging, where energy feedback connects occupants with their shared workplace, and social normative information connects individuals with their working community.

The preceding literature review has revealed that a gap in knowledge exists as to whether the combination of energy feedback and social normative information affects human subjective thermal evaluation of an environment. This study takes what is believed by the authors to be the first step towards investigating this matter and to filling this knowledge gap. The context for our investigation is that of a shared-space office replicated within a controlled environment. The aim is to look for any effects across a range of realistic 'warm' temperatures in the first instance, as might be encountered in offices during summer periods.

The study is important because, if messaging is shown to affect human comfort evaluation and/or subsequent appliance usage, then it may herald a future means for managing comfort and cooling energy demand in multi-occupant offices provided that health and well-being are not compromised. This, together with the worldwide prevalence of multi-occupant offices, could lead to an important contribution towards meeting the global challenge of reducing cooling energy demand while maintaining thermal comfort.

\section{Methodology}

Information feedback messaging was developed for implementation via individual desk-based computers within a multi-occupant setting, with experiments being conducted under the controlled conditions afforded by an environmental room. Each occupant would remain sedentary at their work location throughout their session and without access to adaptive opportunities. In this way, the psychological component of adaptation could be allowed to vary, whilst physiological and behavioural components remained constant and controlled.

The experimental programme was designed to investigate test subjects' responses for situations without feedback messaging, with feedback messaging (these appearing at the outset, or during, a session, as well as allowing a 'control group' comparison), and across a range of summer office temperatures. The purpose of this was to identify the extent to which indoor temperatures might affect responses (if any), as an aid to 
designing a further stage of experimental work (to be conducted and subsequently reported). The study also investigated the intention to use energy-consuming appliances (actual usage will be examined in a future experiment). All experiments involved human participants and satisfied the requirements of the Ethics Approvals (Human Participants) Sub-Committee at Loughborough University.

\subsection{Feedback messaging design}

Considering the working environment of open-plan offices, messaging in this study was designed as a combination of energy feedback and social normative information that can inform occupants about their and their colleagues' behaviour. Such a comparison could potentially lead occupants to follow the pro-environmental behaviour of others. For our study, the design had to account for the fact that this was an 'artificial' environmental room-based situation, and this was achieved through use of artificial data on energy consumption (see later).

In previous studies (Staddon et al., 2016), positive messaging had been shown to be an effective means for encouraging good energy behaviour. Though there has been little work reported on the effects of negative messaging, we nevertheless opted in our study to maintain the positive messaging perspective so as to increase the chance of observing any potential effects (if present), without introducing an additional, potentially influencing, factor. The positive messaging employed was designed to be delivered to participants via a laptop screen image and in the context of an office desk personal comfort system as shown in Figure 1.

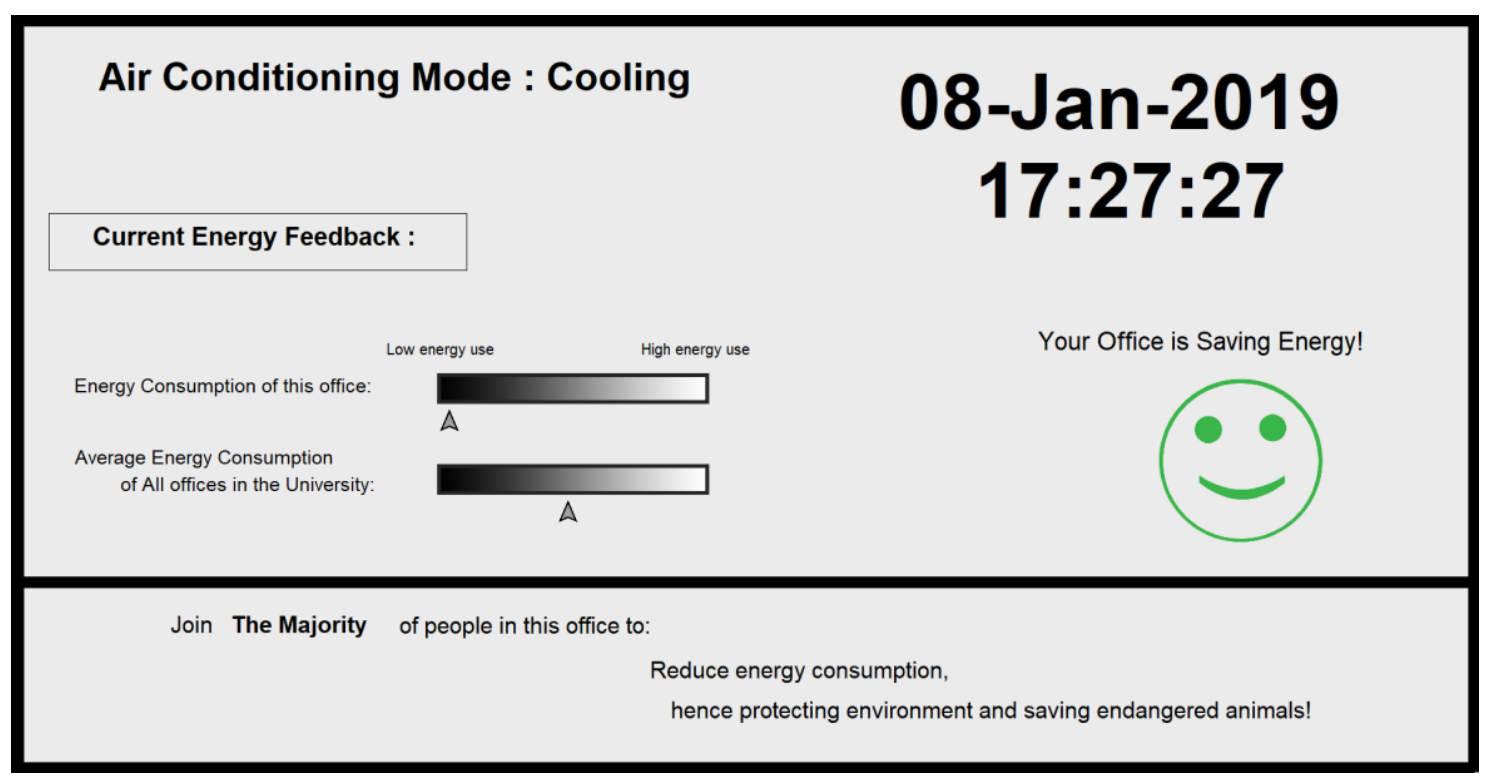

Figure 1 Schematic diagram of the feedback messaging for display screens (energy consumption scales display artificial data only for the purpose of this study).

The messaging was comprised as follows: i) energy feedback - in the form of comparison between an individual's current energy use and the average energy use at a group level (note that these were artificial data for the purpose of this study); ii) 
injunctive norms - in the form of 'approval' (via 'smiling face') of the current (though artificial) energy-use behaviours; iii) descriptive normative sentences - "Join the majority of people in this office to reduce energy consumption, hence protecting environment and saving endangered animals" (this sentence was chosen to cover a broad spectrum of eco-friendly values - energy; environment; wildlife). The screens also displayed the 'air-conditioning mode', date and time. Specifically, air-conditioning (though not the actual means of generating the room conditions) was always shown as in "cooling" mode, in order to remind participants that they were in 'office summertime' conditions, while actual date and time were displayed so as to attract occupants' attention to the laptop display screen. When messaging appeared, it remained visible to the participants on their computer screens throughout the required period (see Section 2.5).

In addition, since colour might influence people's performance, mood and perceptions (Stone, 2001), all screen contents were presented in black-and-white format, except for the "green" smiling face. This is because this emotional face is designed to deliver the injunctive normative information and "green" is often regarded as a symbol of safety and approval by the majority of people globally (Vasiljevic et al., 2015).

\subsection{Questionnaires design}

Two types of questionnaires (background questionnaire and in-session questionnaire) were designed and issued to each participant via online questionnaire platforms. The questionnaires are shown in Appendices A and B.

Background questionnaires were sent to each participant in advance of their experimental session to collect information on demographics and existing personal and social beliefs, which includes descriptive norms, injunctive norms, collective outcome expectancy (desired outcomes resulted from collective actions) and goal attractiveness (the estimated importance of the goal). These questions were based on Carrico and Riemer's questionnaire (2011) and modified for the present study. Following these main questions, three additional questions were asked about preferred music type and listening to music in offices, in order to prevent participants from guessing the real aim of the study before their test.

In-session questionnaires were sent via emails to each participant's laptop or smartphone every fifteen minutes during their test. The questions covered whole-body thermal sensation (ASHRAE's seven-point scale), thermal comfort, thermal acceptability, thermal satisfaction, thermal preference, thermal tolerance and the intended use behaviour of personal cooling devices and desk fans (actual devices and fans were not utilised in this study). Specifically, to enhance the detail in reporting thermal sensation, the ASHRAE seven-point scale for thermal sensation was extended to 31 points allowing more sub-options for response, as shown in Appendix B.

\subsection{Subjects and recruitment}


The targeted participants for the study were office workers or those with previous office-working experience. Recruitment took place throughout Loughborough University, with the majority of participants being $\mathrm{PhD}$ students and staff. All participants completed a basic health screening questionnaire confirming their general good health, that is, recruited participants reported no known health issues that could potentially influence their results in the study.

Successfully-recruited participants were sent detailed experiment information, including a briefing introduction, time slot and clothing requirement. The briefing made clear that the experiment was about thermal comfort in workplaces in summer conditions, but deliberately made no mention about messaging or its role. Table 1 shows the clothing requirement for both males and females, and all participants were asked to follow this guidance and to wear their own ensemble, giving a total clothing thermal insulation value of 0.57 clo.

Table 1 - Clothing insulation requirement for participants

\begin{tabular}{|c|c|}
\hline \multicolumn{2}{|c|}{ Clothing requirement for males } \\
\hline Item & Clothing insulation (clo) \\
\hline Men's briefs & 0.04 \\
\hline shoes & 0.02 \\
\hline calf-length socks & 0.03 \\
\hline T-shirt & 0.08 \\
\hline long-sleeve dress shirt & 0.25 \\
\hline Trousers (thin) & 0.15 \\
\hline Total & 0.57 \\
\hline Clothing requirement for females \\
\hline Item & Clothing insulation (clo) \\
\hline Women's Briefs & 0.04 \\
\hline shoes & 0.02 \\
\hline calf-length socks & 0.03 \\
\hline T-shirt & 0.08 \\
\hline long-sleeve dress shirt & 0.25 \\
\hline Trousers (thin) & 0.15 \\
\hline Total & 0.57 \\
\hline
\end{tabular}

In total, sixty-two people ( 23 female and 39 male) took part in the study, which comprised experiments at three temperature conditions, each experiment being of two hours duration: no messaging throughout (9 participants); appearance of messaging at second hour (27 participants); appearance of messaging at first hour (i.e. at the start) with removal at second hour (26 participants). Each participant took part only once (no repeat testing). Demographic information is shown in Table 2.

Table 2 - Average demographic information of participants

\begin{tabular}{cccccc}
\hline & Gender & Age & Weight (Kg) & Height (cm) & BMI \\
\hline \multirow{3}{*}{ No messaging } & Female & $33.6(12.26)$ & $57.9(7.08)$ & $162.3(3.23)$ & $22.0(2.33)$ \\
\cline { 2 - 6 } & Male & $30.3(1.89)$ & $80.5(2.89)$ & $179.5(4.80)$ & $25.0(1.83)$ \\
\cline { 2 - 6 } & All & $32.1(8.92)$ & $68.0(13.02)$ & $169.9(9.80)$ & $23.3(2.57)$ \\
\hline & Female & $34.6(8.42)$ & $61.7(6.47)$ & $163.7(5.15)$ & $27.4(12.70)$ \\
\hline
\end{tabular}




\begin{tabular}{cccccc}
\hline Messaging at & Male & $28.8(5.08)$ & $76.3(11.60)$ & $177.3(7.48)$ & $24.2(2.40)$ \\
\cline { 2 - 6 } second hour & All & $30.3(6.48)$ & $72.5(12.26)$ & $173.7(9.14)$ & $25.0(6.60)$ \\
\hline \multirow{2}{*}{$\begin{array}{c}\text { Messaging at } \\
\text { first hour }\end{array}$} & Female & $27.2(3.06)$ & $58.6(9.00)$ & $164.5(5.70)$ & $21.6(2.77)$ \\
\cline { 2 - 6 } & Male & $28.9(7.32)$ & $80.2(15.50)$ & $178.6(5.49)$ & $25.1(4.49)$ \\
\cline { 2 - 6 } & All & $28.2(5.88)$ & $71.1(16.88)$ & $172.6(8.98)$ & $23.6(4.18)$ \\
\hline
\end{tabular}

Note: Numbers in parentheses are standard deviations

For each experiment, the average age of participants ranged from 27 to 35 years and the average value of body mass index (BMI) ranged from 23 to 25 , though the group of female participants in the experiment with messaging at second hour had a slightly higher BMI than other groups as a result of random allocation. Of all participants, $94 \%$ normally spent the majority of their time in offices, and about $87 \%$ worked at least 4 hours in an office on a typical working day.

\subsection{Environmental room and facilities}

The environmental room used for the study is located in the School of Architecture, Building and Civil Engineering at Loughborough University, UK. The room is $5.4 \mathrm{~m}$ long, $3 \mathrm{~m}$ wide and $2.8 \mathrm{~m}$ high, with a window in the south wall, as shown in Figure 2.

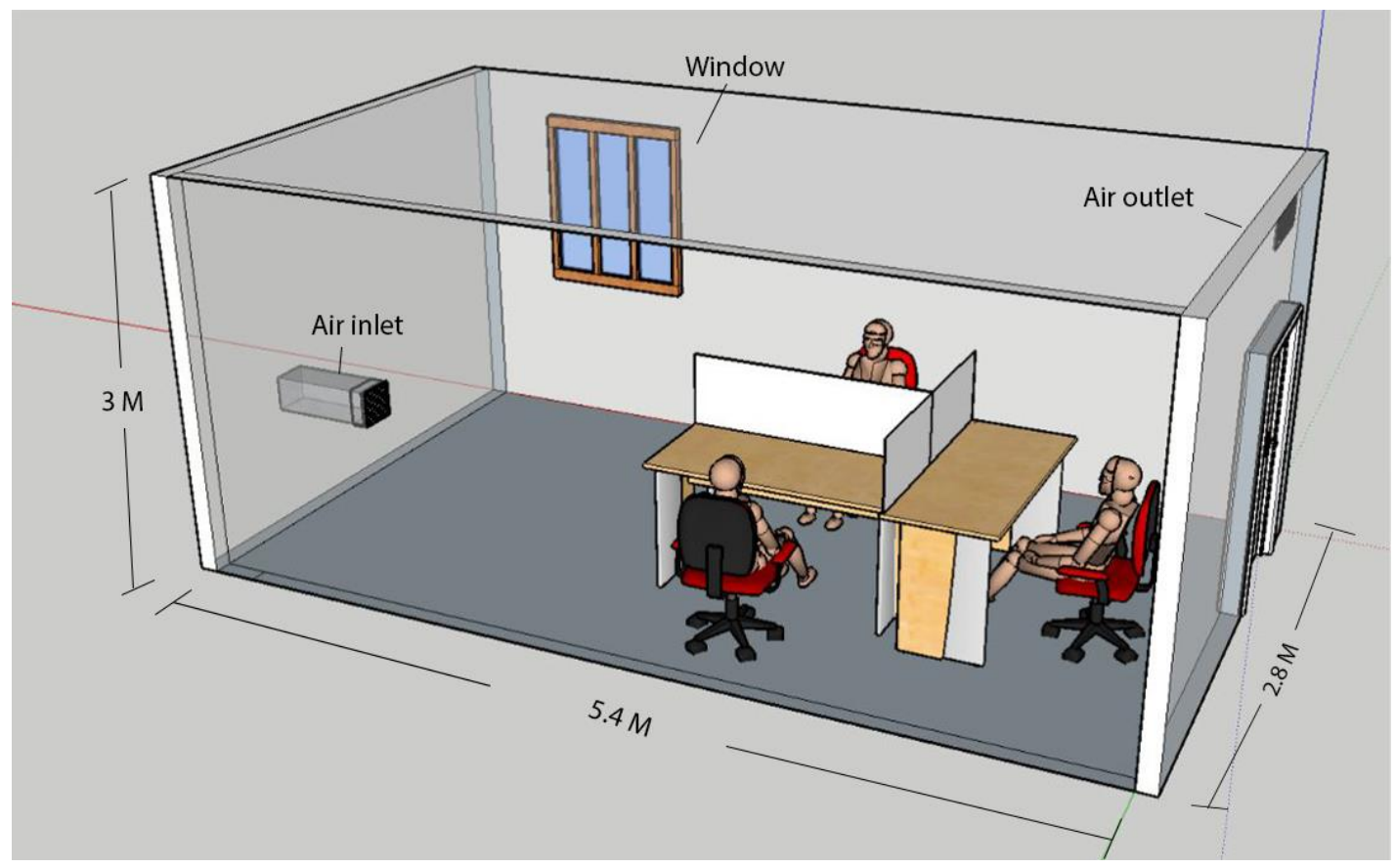

Figure 2 - Environmental room layout

Walls are clad with Frenger panels overlaid with plastic finishing panels to allow control of wall surface temperatures. The window is composed of seven layers of glazing, in order to minimise temperature differences between walls and window (Loveday et al., 2002). The room was arranged to represent an open-plan multi-occupant office. Three workstations were set up and separated by partitions as shown in Figure 2. Each work station was provided with a power socket, a laptop and an LED desk light. Standard 
office chairs were used, giving 0.1 clo thermal insulation to be added to the ensemble clothing insulation worn by the subjects (ASHRAE 55, 2013). Ventilation rates in tests were set to be higher than the minimum requirement to ensure acceptable indoor air quality for subjects throughout the tests.

Environmental parameters were measured using ComfortSense kits from DANTEC DYNAMICS throughout the period of the tests. Air temperature and air velocity were measured using a $54 \mathrm{~T} 35$ probe (for air temperature: range $-20^{\circ} \mathrm{C}$ to $+80^{\circ} \mathrm{C}$, accuracy: $<0.2 \%$ of reading per $1^{\circ} \mathrm{C}$ change in air temperature; for air velocity: range $0.1-30 \mathrm{~m} / \mathrm{s}$, accuracy: $\pm 2 \%)$. Air temperature and velocity were measured at three heights above the floor $(0.1 \mathrm{~m}, 0.6 \mathrm{~m}$ and $1.1 \mathrm{~m})$. Humidity was measured with a $54 \mathrm{~T} 37$ probe (range: $0-100 \% \mathrm{RH}$; accuracy: $+1.5 \% \mathrm{RH}$ ), while operative temperature was measured using a probe $54 \mathrm{~T} 38$ (range: $0-45^{\circ} \mathrm{C}$; accuracy: $\pm 0.2 \mathrm{~K}$ ).

\subsection{Experimental procedure}

The primary purpose of this study was to investigate the effect of positive feedback messaging in an open plan office context in summertime conditions. Three thermal conditions were created: $24.5^{\circ} \mathrm{C}, 27^{\circ} \mathrm{C}$ and $29.5^{\circ} \mathrm{C}$, simulating the indoor air temperatures that can occur in offices during warm summer conditions. Air temperature was maintained equal to mean radiant temperature; air velocity was kept lower than $0.1 \mathrm{~m} / \mathrm{s}$; humidity remained in the range $30-50 \%$ for the majority of tests.

As stated in Section 2.3, three experiments were devised, each of two hours' duration: i) no messaging, with conditions maintained at steady state throughout, for the three temperatures ( 9 participants, 3 per temperature condition) - to check steadiness of responses, and compare reported thermal sensation with PMV prediction (for reference); ii) messaging at second hour, for the three temperatures (27 participants, 9 per temperature condition) - to observe whether the appearance of messaging affected responses; iii) messaging at first hour, then removed at second hour, for the three temperatures (26 participants, 8-9 per temperature condition, with one missing) - to reverse the order and observe whether presence, then removal, of messaging affected responses. Figure $3 \mathrm{a}, 3 \mathrm{~b}$ and $3 \mathrm{c}$ illustrate the procedure applied.

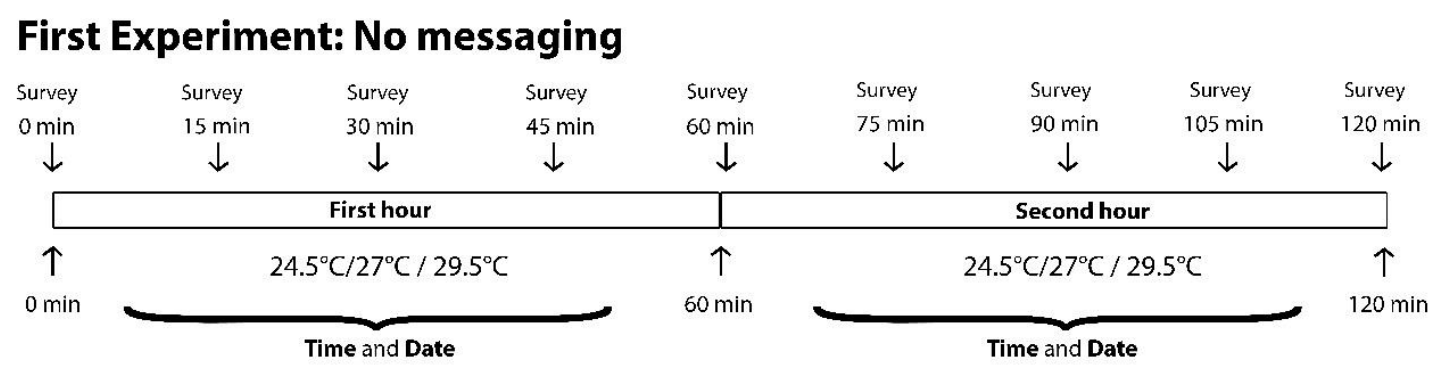




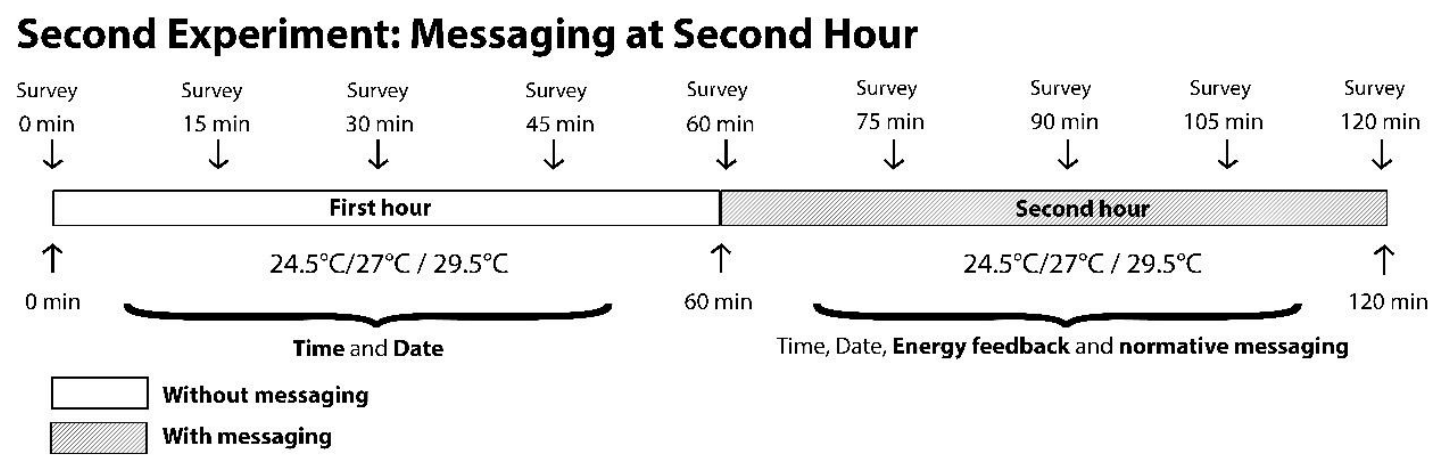

\section{Third Experiment: Messaging at First Hour}

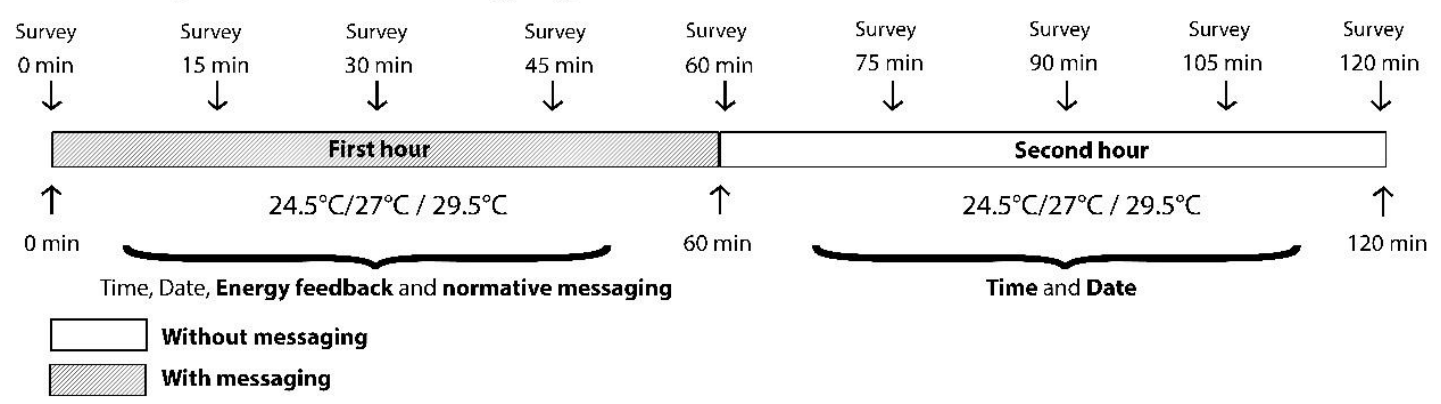

Figure 3 Procedure of three experiments: (a) no messaging (top); (b) messaging appears at second hour (middle); (c) messaging present at first hour, then removed at second hour.

To ensure unbiased subject allocation, the method of block randomization was adopted, which balanced participants' individual differences and time-related variables. In this way, seven blocks were set for the study, and, in each block, three thermal conditions were randomly ordered by using a table of random numbers. Participants were randomly allocated into each block, and anonymously coded by reference number from 1 to 63 . Subjects arrived 30 minutes before their test started and stayed in the acclimation room next to the environmental room, in order to reduce their metabolic rate to a sedentary level.

All tests were conducted in the same month (October 2018) to minimise seasonal influences, and at the same time of day (2.00-4.00PM) on different days to minimise potential diurnal influences. Each test lasted two hours, and with three participants at a time, one at each work station, without view of each other, and no inter-participant communication. Participants were free to do their own office work, and metabolic rates were evaluated as 1.1 Met.

During each test, air temperature, mean radiant temperature, air velocity and humidity were recorded automatically (details in section 2.4). Messaging, as shown in Figure 1, was displayed on laptop screens at each work station, as per the experimental regime discussed. Screens remained switched on, and continuously displayed the relevant date and time, throughout each two-hour session.

Questions regarding current whole-body thermal sensation, thermal comfort, acceptability, preference, satisfaction, tolerance and energy-use behaviour, were sent 
to each participant every 15 minutes via online questionnaire. Considering the time needed to reach thermal equilibrium is around 30 minutes (Arens et al., 2006), responses obtained after 45 minutes were regarded as suitable for analysis.

\subsection{Data Analysis}

The experiment was designed as a 'within subjects' comparison for minimising effects of personal differences and hence maximising effectiveness of the sample size. The design also allowed for a 'control group' comparison. Statistical tests were selected accordingly. Responses to questionnaires were collected from participants and were used to analyse the effect of feedback messaging on participants' thermal evaluation and intended behaviour towards using personal comfort systems. Analysis is based on the paired T-test to compare each participant's changes of reported thermal sensation with/without feedback messaging and uses Wilcoxon Signed Ranks Test to compare each participant's changes of intended behaviour and other thermal evaluations (comfort, acceptability, preference, satisfaction and tolerance). To compare between-group differences for effective "control-group" comparison, the independent T-test and Mann Whitney U Test were used to compare differences between the results of second experiment and third experiment.

\section{Results}

The required thermal conditions $\left(24.5^{\circ} \mathrm{C}, 27^{\circ} \mathrm{C}\right.$ and $\left.29.5^{\circ} \mathrm{C}\right)$ were closely maintained throughout the tests, with a fluctuation of no more than $\pm 0.5^{\circ} \mathrm{C}$. All participants successfully completed their test sessions, with the exception of only one participant who did not appear $\left(29.5^{\circ} \mathrm{C}\right.$, third experiment - messaging at first hour). In total, 62 valid responses were gathered to the background questionnaire, and 372 valid responses to the in-session questionnaires. The results of the first experiment (no messaging) were analysed to check steadiness of responses, and compare reported thermal sensation with PMV prediction. To compare the changes in each participants' thermal evaluations as influenced by messaging, results were analysed using inferential statistics techniques for the remaining two experiments that involved messaging.

\subsection{Participants' background views}

From the background questionnaire, participants' existing views in terms of descriptive norms, injunctive norms, collective outcome expectancy and goal attractiveness were gathered and summarised, for a supposed multi-occupant office context, these responses being gathered prior to any involvement in test sessions.

Regarding descriptive norms, Table 3 summarises the responses to the question about believed behaviour of office colleagues towards thermostat adjustment. Responses are grouped as those taking part with messaging at second hour and first hour, though no-one took part more than once. For both groupings, the collective result 
was that only about $18-19 \%$ of participant responses considered that half or more of colleagues would adjust thermostats to reduce energy consumption.

Table 3 - Responses regarding existing personal and social beliefs (descriptive norms) How many of your office colleagues do you think would adjust heating or cooling thermostats to reduce energy consumption?

\begin{tabular}{ccccccc}
\hline & None & Very few & $\begin{array}{c}25 \% \text { of } \\
\text { colleagues }\end{array}$ & $\begin{array}{c}50 \% \text { of } \\
\text { colleagues }\end{array}$ & $\begin{array}{c}75 \% \text { of } \\
\text { colleagues }\end{array}$ & $\begin{array}{c}\text { Almost } \\
\text { all }\end{array}$ \\
\hline $\begin{array}{c}\text { Messaging at second } \\
\text { hour }\end{array}$ & $29.6 \%$ & $37 \%$ & $14.8 \%$ & $3.7 \%$ & $3.7 \%$ & $11.1 \%$ \\
\hline \begin{tabular}{c} 
Messaging at first hour \\
\hline
\end{tabular} & $3.8 \%$ & $50 \%$ & $26.9 \%$ & $11.5 \%$ & $7.7 \%$ & $0 \%$ \\
\hline
\end{tabular}

Regarding injunctive norms, for both groupings, around $70 \%$ of participant responses revealed that allowing offices to become too cold in summer or too warm in winter was a behaviour that would meet with some degree of disapproval, as shown in Table 4.

Table 4 - Responses regarding existing personal and social beliefs (injunctive norms) What would you think, if your office colleagues let your office condition become too cold in summer or too warm in winter?

\begin{tabular}{lccccc}
\hline & $\begin{array}{c}\text { Strongly } \\
\text { disapprove }\end{array}$ & Disapprove & $\begin{array}{c}\text { Neither } \\
\text { approve nor } \\
\text { disapprove }\end{array}$ & Approve & $\begin{array}{c}\text { Strongly } \\
\text { approve }\end{array}$ \\
\hline Messaging at second hour & $22.2 \%$ & $48.1 \%$ & $25.9 \%$ & $3.7 \%$ & $0 \%$ \\
\hline Messaging at first hour & $23.1 \%$ & $53.8 \%$ & $19.2 \%$ & $3.8 \%$ & $0 \%$ \\
\hline
\end{tabular}

Table 5 and Table 6 show that the majority (about 90\%) of participants' responses indicated the belief that office workers like them can reduce energy consumption by changing their behaviours, and that nearly $80 \%$ of participants' responses suggested that the majority of individuals would like to reduce their personal energy usage.

Table 5 - Responses regarding existing personal and social beliefs (collective outcome expectancy)

By changing our heating/cooling use behaviour, office workers like me can reduce energy consumption in offices

\begin{tabular}{lccccc}
\hline & $\begin{array}{c}\text { Strongly } \\
\text { disagree }\end{array}$ & Disagree & $\begin{array}{c}\text { Neither } \\
\text { disagree nor } \\
\text { agree }\end{array}$ & Agree & $\begin{array}{c}\text { Strongly } \\
\text { Agree }\end{array}$ \\
\hline Messaging at second hour & $0 \%$ & $3.7 \%$ & $7.4 \%$ & $70.4 \%$ & $18.5 \%$ \\
\hline Messaging at first hour & $0 \%$ & $0 \%$ & $11.5 \%$ & $65.4 \%$ & $23.1 \%$ \\
\hline
\end{tabular}

Table 6 - Responses regarding existing personal and social beliefs (goal attractiveness) I would like to reduce the amount of heating/cooling energy that I personally use

\begin{tabular}{lccccc}
\hline \multicolumn{2}{l}{ I would like to reduce the amount of heating/cooling energy that I personally use } \\
\hline $\begin{array}{l}\text { Strongly } \\
\text { disagree }\end{array}$ & Disagree & $\begin{array}{c}\text { Neither } \\
\text { disagree nor } \\
\text { agree }\end{array}$ & Agree & $\begin{array}{c}\text { Strongly } \\
\text { Agree }\end{array}$ \\
\hline Messaging at second hour & $0 \%$ & $0 \%$ & $22.2 \%$ & $44.4 \%$ & $33.3 \%$ \\
\hline Messaging at first hour & $0 \%$ & $3.8 \%$ & $19.2 \%$ & $61.5 \%$ & $15.4 \%$ \\
\hline
\end{tabular}

To summarise, participants generally considered that the majority of office colleagues would not adjust thermostats to reduce energy consumption, would disapprove if office conditions became too cold in summer or too warm in winter, agreed that changing individual heating/cooling use behaviour can reduce energy consumption in offices, and expressed a desire to reduce personal heating/cooling energy usage. In terms of 
the experiments conducted involving messaging, it was considered that participants' views were similar amongst each grouping.

\subsection{No messaging, and stability}

For conditions maintained uniform and stable at each of the three temperatures of interest, the reported whole-body thermal sensation votes of 12 participants at thermal equilibrium, and drawn from across the study, are shown in Figure 4 for each condition, as a function of time in minutes after the start of their session. Here, each dot represents one sensation vote, and the darker the dot then the greater the number of votes at that sensation. The dashed lines show the PMV value calculated using the Berkeley Thermal Comfort Tool (Hoyt et al., 2017) corresponding to each thermal condition, for simple reference purposes. As might be expected under stable conditions and with no access to adaptive opportunities, PMV values are generally similar to reported sensations. Furthermore, the whole-body thermal sensation and thermal comfort can be expected to remain unchanged once people have reached equilibrium in uniform and stable thermal environments (Arens et al., 2006).

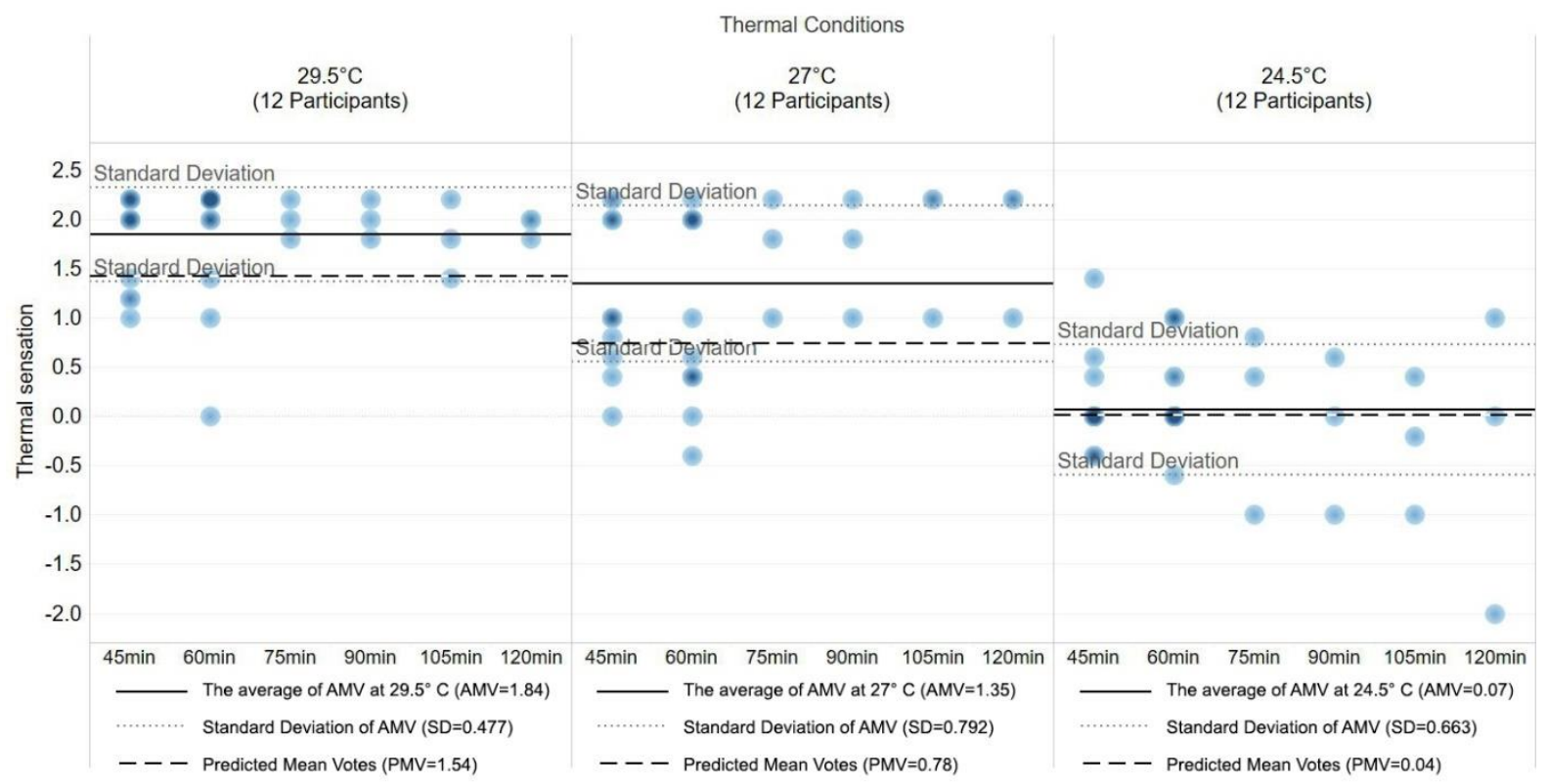

Figure 4 - Reported thermal sensation and PMV at each thermal condition in first experiment (no messaging) (45min to $120 \mathrm{~min}$ )

Based on Figure 4, the PMV was within the range of +/- one standard deviation of the average AMV for each of the three thermal conditions, though the average of participants' thermal sensation was slightly warmer than the PMV predicted. Reported thermal sensations at the warmer conditions $\left(29.5^{\circ} \mathrm{C}\right.$ and $\left.27^{\circ} \mathrm{C}\right)$, showed little variation over time, though wider variation was observed at $24.5^{\circ} \mathrm{C}$. Other subjective evaluations, including thermal comfort, acceptability and satisfaction, remained relatively stable.

\subsection{Messaging at second hour}


This part of the study was designed to observe whether the appearance of messaging affected the subjective responses of the participants across a range of indoor summertime temperatures. Messaging was introduced at the second hour of each twohour test session, for each of the three room temperature conditions (27 participants in total, 9 participants per condition).

\subsubsection{Thermal sensation}

Considering all thermal conditions and all twenty-seven participants as a whole, the average thermal sensation reported by participants after the appearance of messaging was found to be lower (cooler) than that without messaging. A paired t-test showed that the difference between the periods with/without messaging was significant $(\mathrm{t}=$ 3.156 , $d f=26, p=0.004$, two-tailed, Cohen's $d=0.59$ ), as shown in the last row of Table 7.

Table 7 - the comparison of thermal sensation before/after messaging, for the three thermal conditions

\begin{tabular}{|c|c|c|c|}
\hline Conditions & $\begin{array}{c}\text { Thermal sensation without } \\
\text { messaging }\end{array}$ & $\begin{array}{c}\text { Thermal sensation with } \\
\text { messaging }\end{array}$ & Statistical significance \\
\hline $24.5^{\circ} \mathrm{C}$ & $0.11(0.348)$ & $-0.13(0.146)$ & Not significant \\
\hline $27^{\circ} \mathrm{C}$ & $1.08(1.018)$ & $0.94(1.166)$ & Not significant \\
\hline $29.5^{\circ} \mathrm{C}$ & $1.73(0.616)$ & $1.43(0.765)$ & $\mathrm{p}=0.050$ \\
\hline All & $0.97(0.967)$ & $0.75(1.021)$ & $\mathrm{p}=0.004$ \\
\hline
\end{tabular}

Note: Numbers in parentheses are standard deviations

When looking at thermal conditions individually, only at $29.5^{\circ} \mathrm{C}$ (Figure 5a) was thermal sensation after the appearance of messaging significantly lower than that without messaging ( $t=2.30, d f=8, p \leq 0.05$, two-tailed, $d=0.43)$, while effect size is large (Cohen's $d=0.77$ ). For the other thermal conditions, no significant difference in thermal sensation was observed. However, the majority of participants at conditions of $24.5^{\circ} \mathrm{C}$ and $27^{\circ} \mathrm{C}$ did report a lower thermal sensation after messaging had been delivered, as shown in Figure 5 (b) and (c). Figure 5 also indicates that the thermal sensation of the majority of participants tends towards the direction of neutral (neither hot nor cold, $T S V=0$ ) after appearance of messaging.

\subsubsection{Other thermally-related evaluations}

Each participant's subjective evaluations (thermal comfort, acceptability, preference, satisfaction and tolerance) without/with messaging were analysed by Wilcoxon Signed Ranks Test. As regards thermal comfort, participants were found to report being more thermally comfortable after the appearance of messaging at the second hour at the warmer conditions $\left(27^{\circ} \mathrm{C}\right.$ and $\left.29.5^{\circ} \mathrm{C}\right)$, compared to that without messaging $(z=-2.021$, $\mathrm{N}$-Ties $=10, \mathrm{p}=0.043$, two-tailed), and this was significant at the $95 \%$ level. 


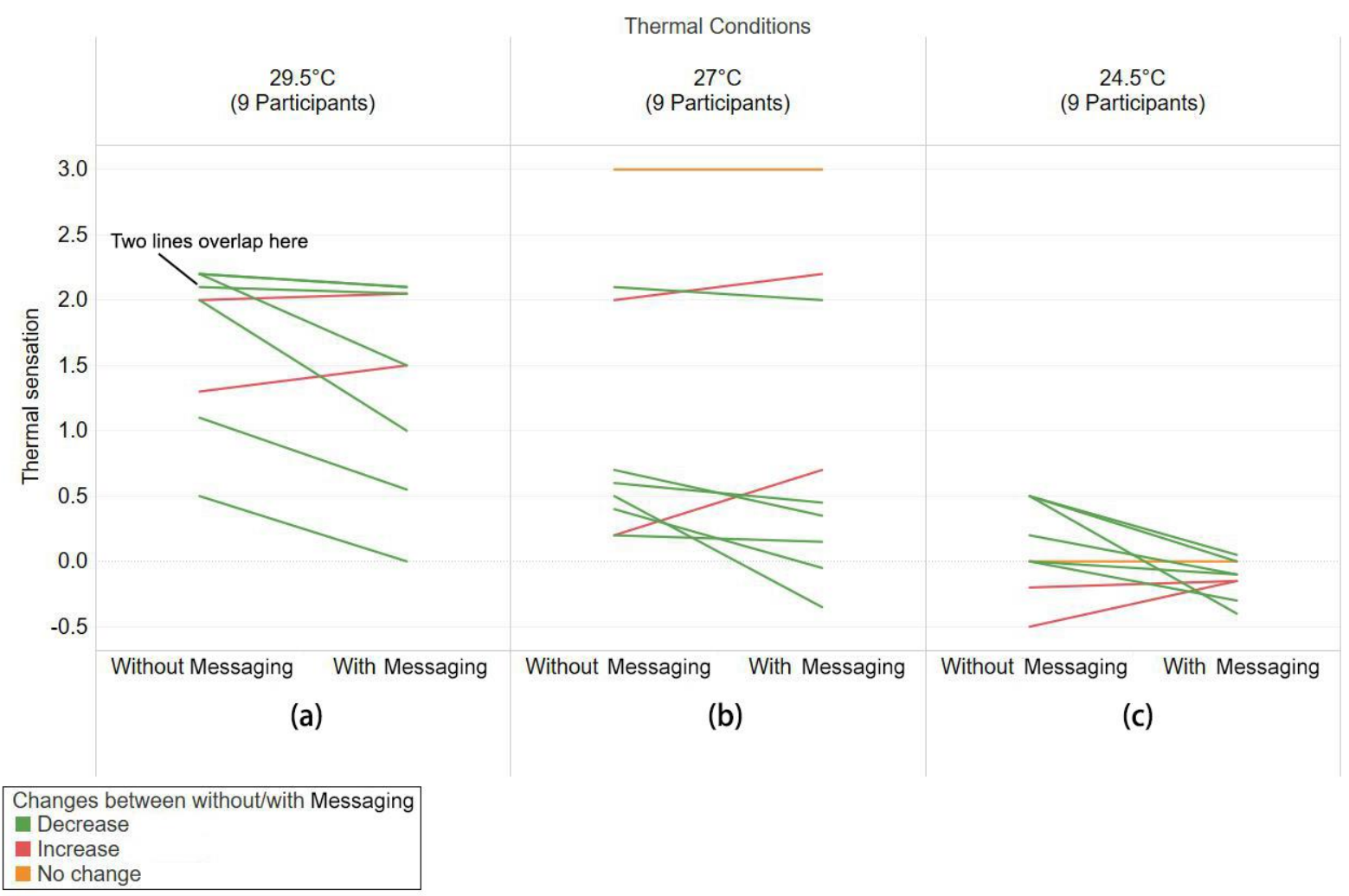

Figure 5 - the comparison of each participant's thermal sensation without/with messaging at different thermal conditions (left-29.5 $5^{\circ} \mathrm{C}$, middle- $27^{\circ} \mathrm{C}$, right-24.5 ${ }^{\circ} \mathrm{C}$ ), (messaging appearing at second hour)

However, thermal acceptability, preference, satisfaction and tolerance did not show any statistically-significant difference after the appearance of messaging. Nevertheless, it is interesting to show the changes that were observed using the following frequency graphs, these being especially noticeable at the warmer conditions.

As shown in Figure 6, thermal comfort appears to be improved in the warmer conditions above $24.5^{\circ} \mathrm{C}$, and especially at the condition of $29.5^{\circ} \mathrm{C}$. At $29.5^{\circ} \mathrm{C}$, nearly $30 \%$ of participants changed from 'uncomfortable' to 'comfortable' after receiving messaging, with nearly $80 \%$ of results reported showing that participants felt thermally comfortable. Although the total percentage of participants who felt comfortable did not change at $27^{\circ} \mathrm{C}$, about $10 \%$ of participants reported feeling 'very comfortable' from 'comfortable', after the messaging was displayed. However, an interesting reverse effect occurred at the condition $24.5^{\circ} \mathrm{C}$ - here more participants reported feeling less comfortable at the second hour, after receiving the messaging. 


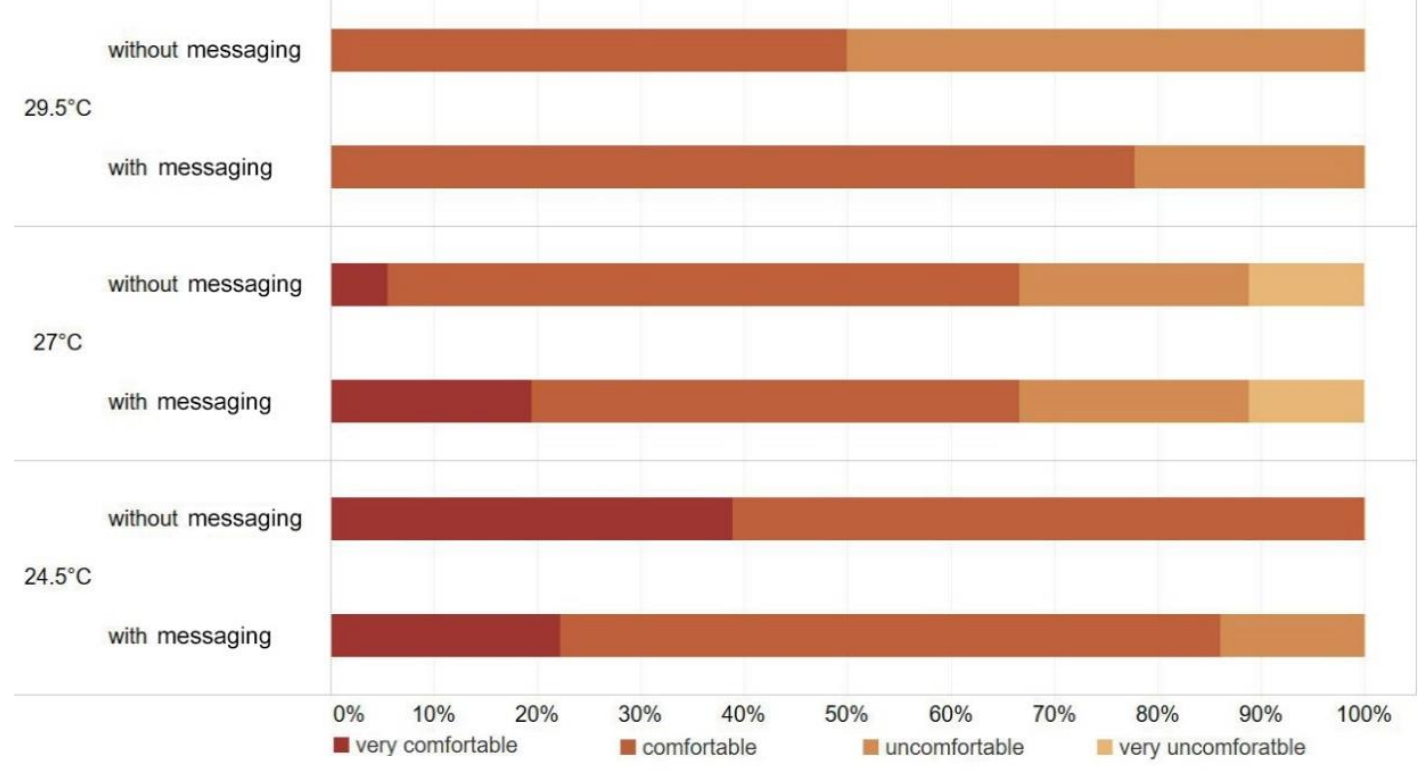

Figure 6 - The comparison of thermal comfort without and with messaging at three thermal conditions (messaging appearing at second hour) ( $\mathrm{n}=27$ total, 9 per condition)

A similar pattern was observed for thermal acceptability (Figure 7), with messaging clearly showing an impact at the condition of $29.5^{\circ} \mathrm{C}$. With messaging appearing at the second hour in the two-hour tests, nearly $40 \%$ of responses illustrated a change to accept the current thermal condition $\left(29.5^{\circ} \mathrm{C}\right)$. More than $95 \%$ of responses following the appearance of messaging showed that participants found conditions to be thermally acceptable at $29.5^{\circ} \mathrm{C}$, even higher than that at $27^{\circ} \mathrm{C}$.

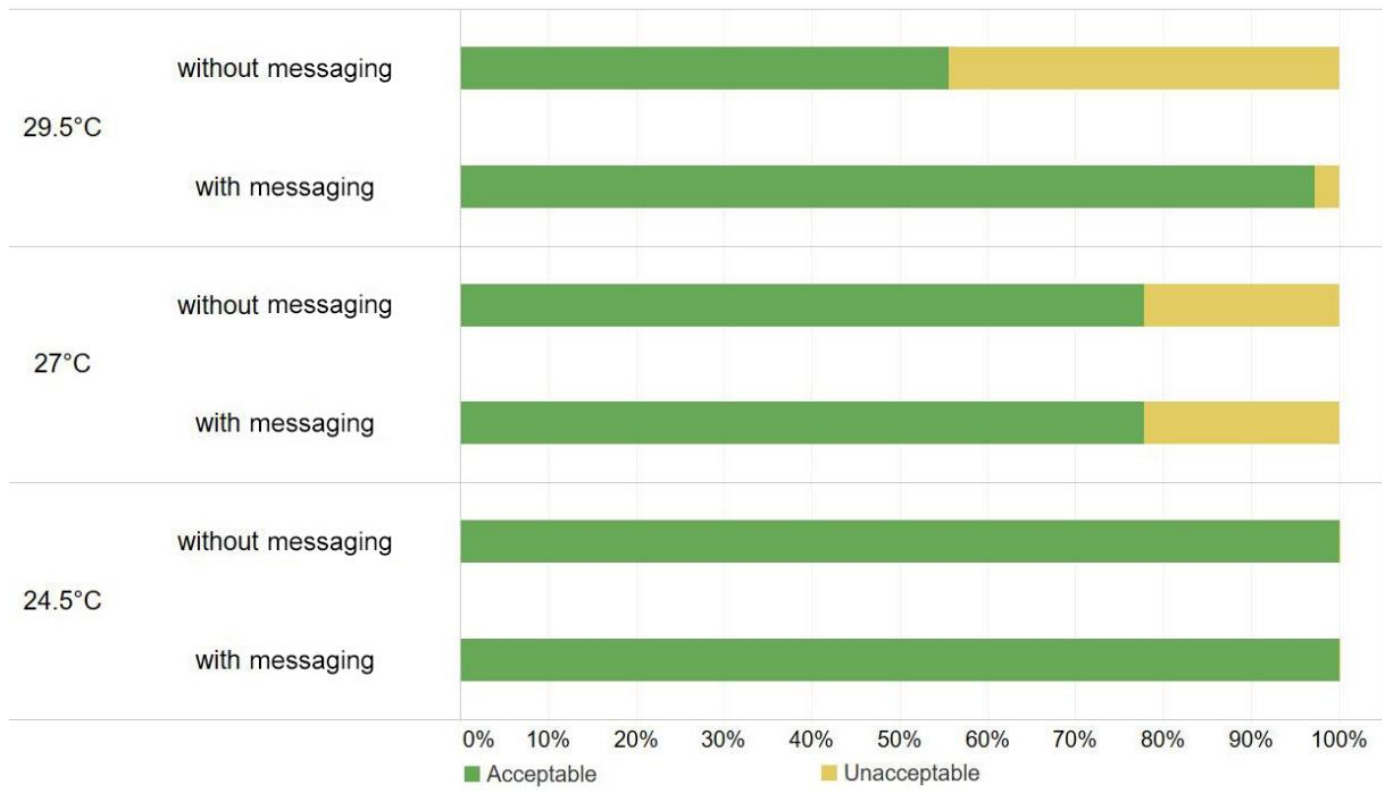

Figure 7 - The comparison of thermal acceptability without and with messaging at three thermal conditions (messaging appearing at second hour) ( $\mathrm{n}=27$ total, 9 per condition)

As shown in Figure 8, an increase in reported thermal satisfaction from $44 \%$ to $81 \%$ was observed at the $29.5^{\circ} \mathrm{C}$ thermal condition following the appearance of messaging 
at the second hour. However, at $27^{\circ} \mathrm{C}$ and $24.5^{\circ} \mathrm{C}$ conditions, reported satisfaction showed a slight decrease (by $3 \%$ and $13 \%$, respectively) after messaging was delivered. Meanwhile, slight increases were observed in the thermal tolerance responses at both the thermal conditions of $27^{\circ} \mathrm{C}$ and $29.5^{\circ} \mathrm{C}(14 \%$ and $8 \%$, respectively) (Figure 9).

Figure 10 shows that the appearance of messaging did not make any apparent difference to participants' thermal preference at the $29.5^{\circ} \mathrm{C}$ condition. However, at $27^{\circ} \mathrm{C}$, the appearance of messaging led to an additional $20 \%$ of responses showing that participants would prefer no change to their thermal environment.

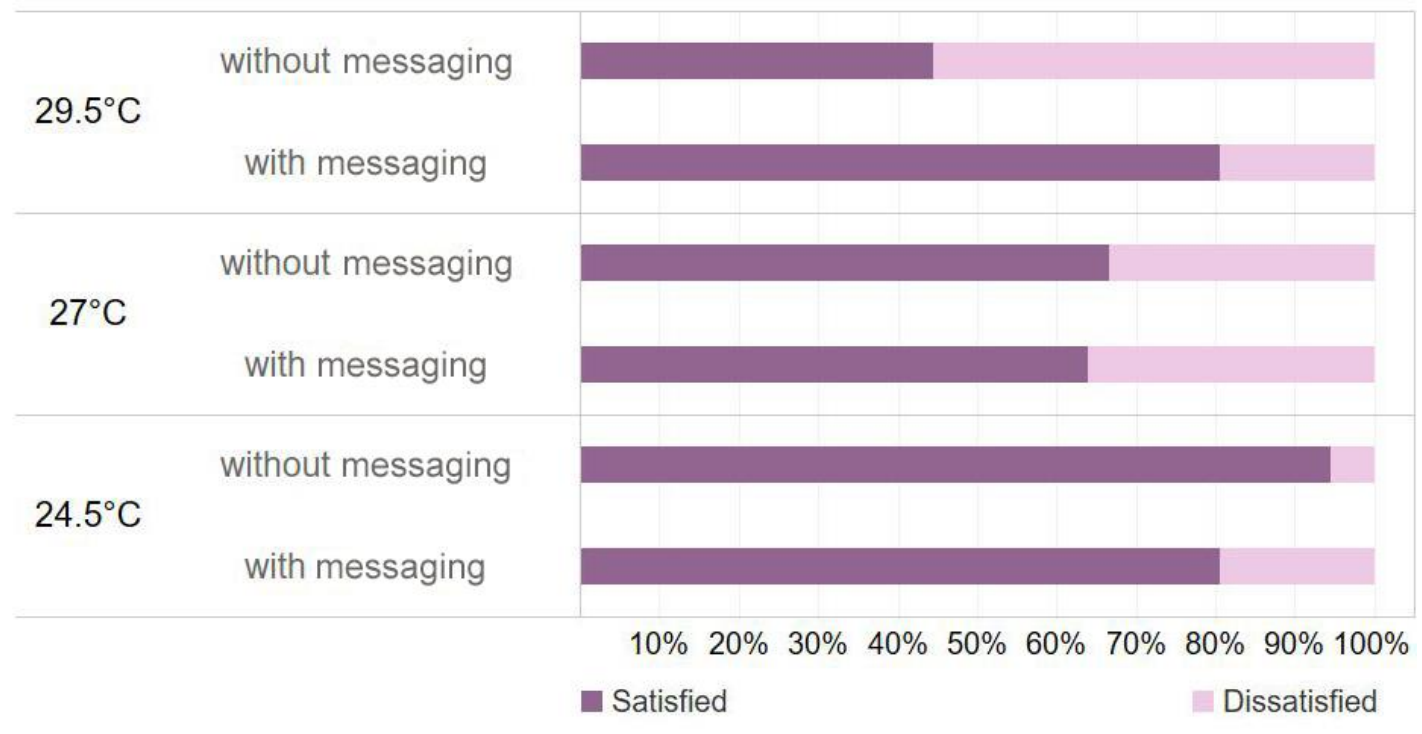

Figure 8 - The comparison of thermal satisfaction without and with messaging at three thermal conditions (messaging appearing at second hour) ( $\mathrm{n}=27$ total, 9 per condition)

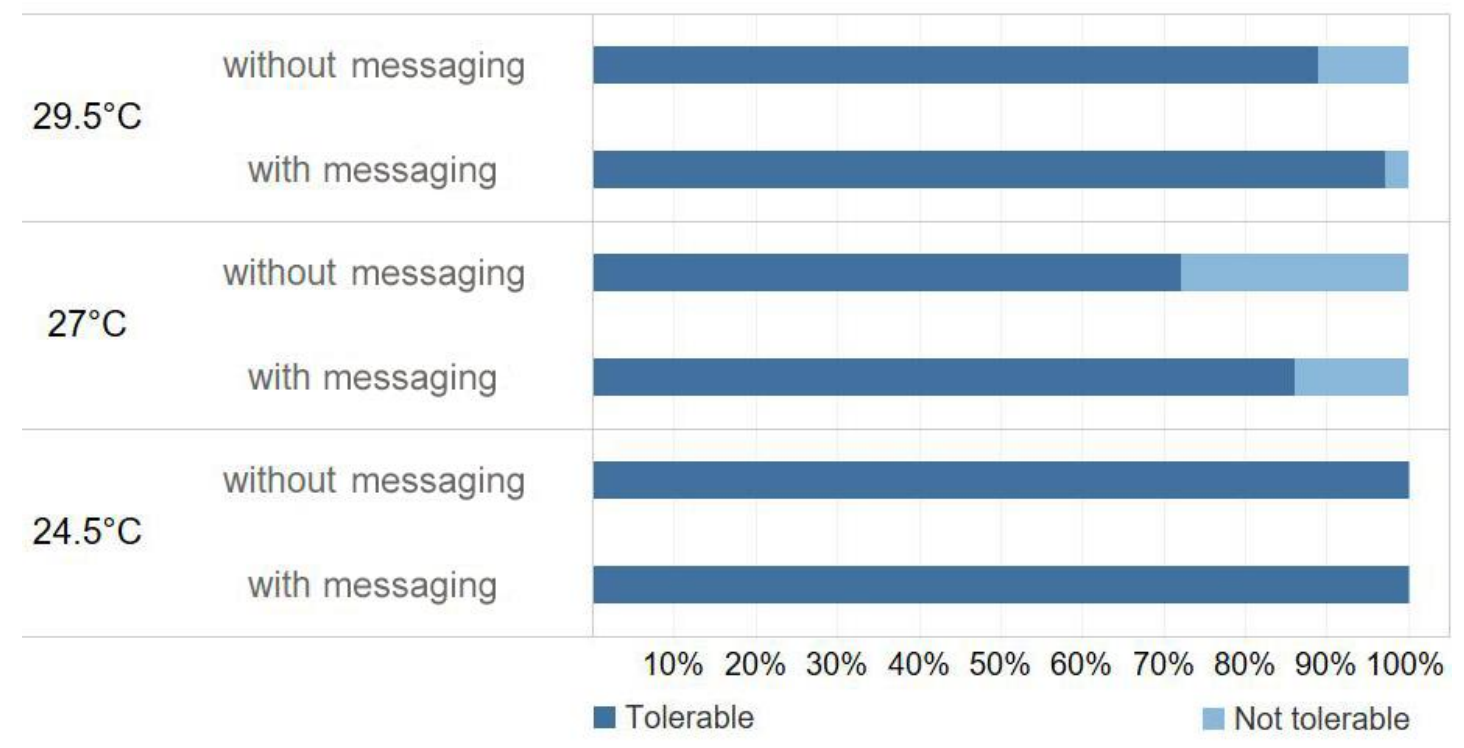

Figure 9 - The comparison of thermal tolerance without and with messaging at three thermal conditions (messaging appearing at second hour) ( $\mathrm{n}=27$ total, 9 per condition) 


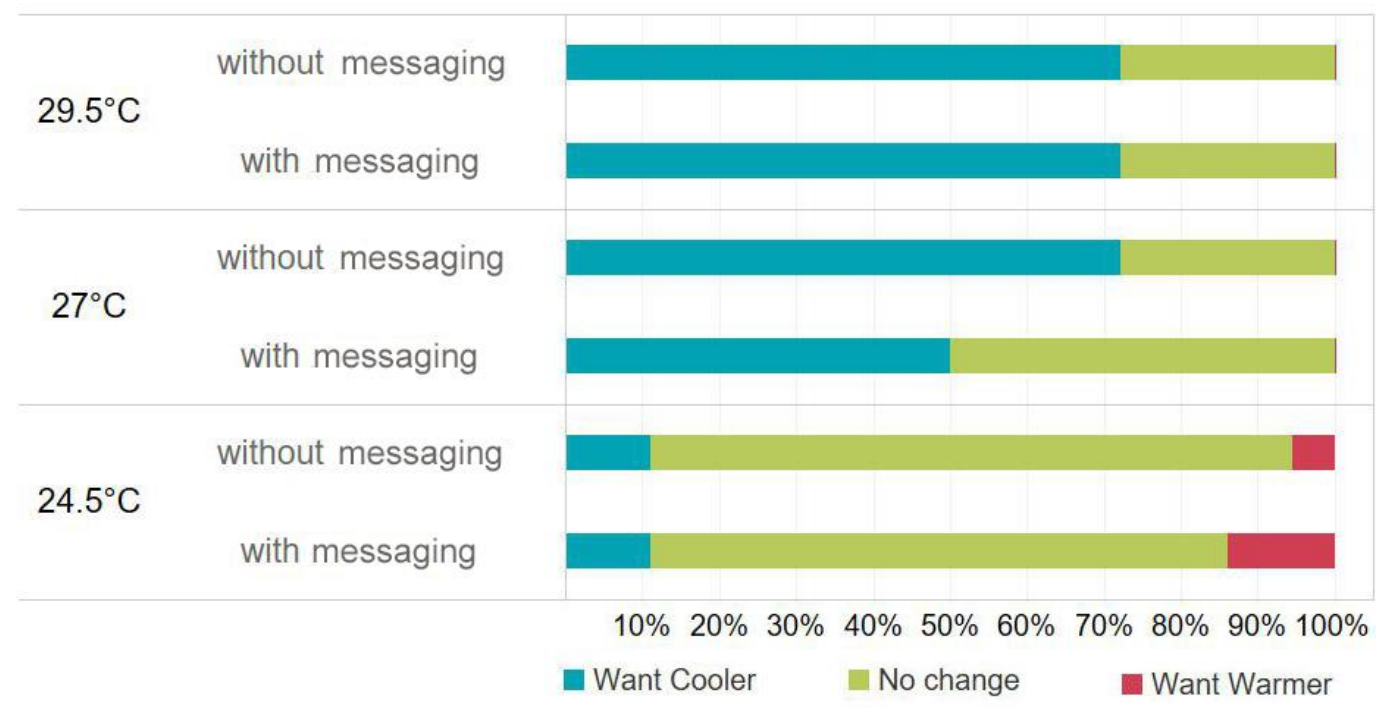

Figure 10 - The comparison of thermal preference without and with messaging at three thermal conditions (messaging appearing at second hour) ( $\mathrm{n}=27$ total, 9 per condition)

\subsubsection{Energy-use behaviour}

In order to investigate whether messaging affects reported intention to use energyconsuming devices for improving personal comfort in an office context, participants in the test sessions were asked two questions about their potential energy-use behaviours with personal comfort systems. The first question was: "If you now had control of a cooling device that affected just yourself, how would you use it right now?", while the second question was "If you had a small desk fan available, how would you use it right now?". The choices of responses to these questions were also accompanied by the corresponding consequence of energy usage. For example, the response choice 'I would like to turn the fan on' is followed by the sentence 'here, this would use more energy', as shown in Appendix B.

Figure 11 shows participants' responses for the situations with and without messaging as to how they would use personal cooling devices. At the thermal conditions $24.5^{\circ} \mathrm{C}$ and $27^{\circ} \mathrm{C}$, responses about using personal cooling devices were consistent with the results of reported thermal preference that are shown in Figure 10. However, at the $29.5^{\circ} \mathrm{C}$ thermal condition, this consistency no longer held, namely that more participants would make no change to cooling device usage (so as to use the same amount of energy), even if they preferred to be cooler. 


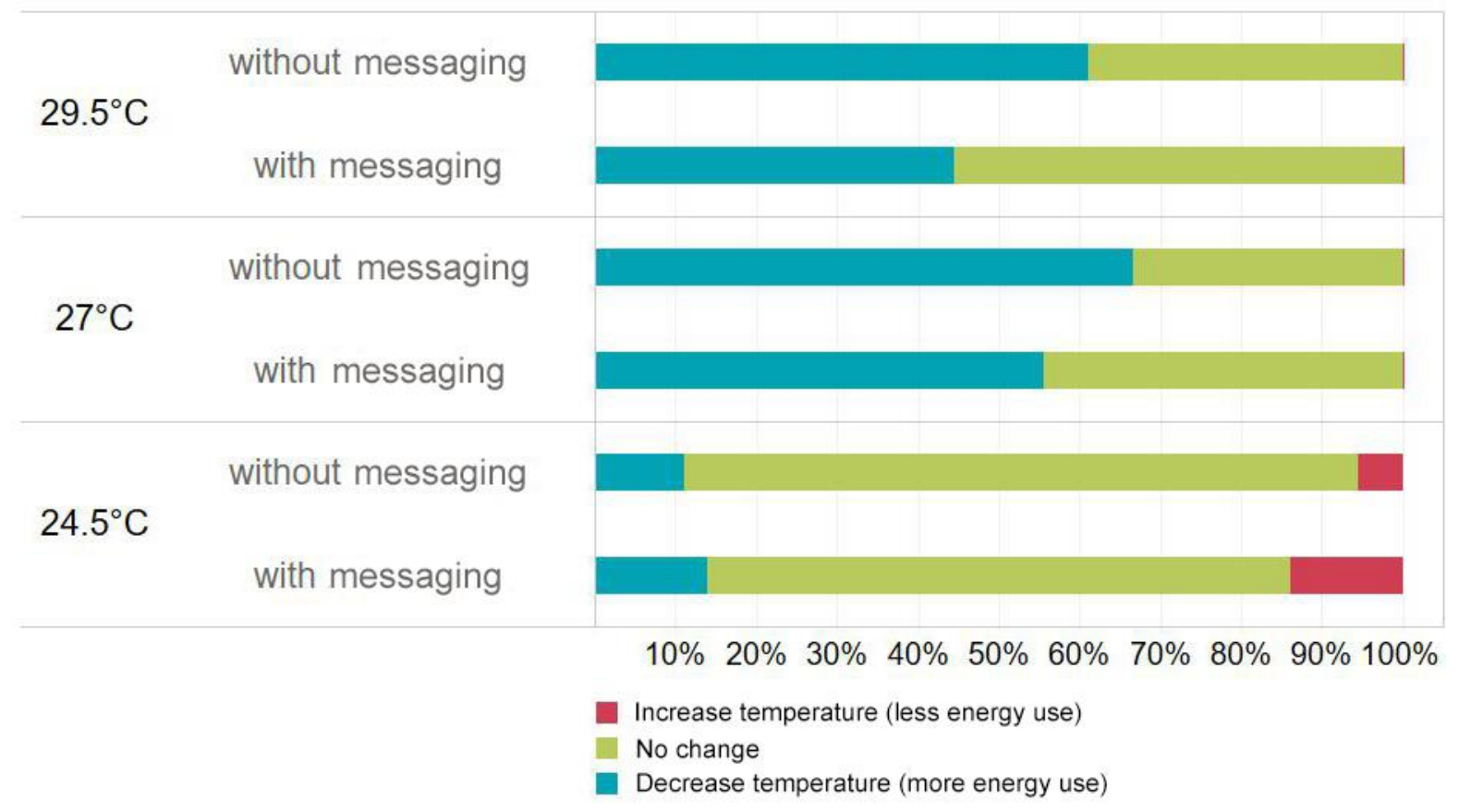

Figure 11 - The comparison of intended cooling device usage without and with messaging at three thermal conditions (messaging appearing at second hour) ( $\mathrm{n}=27$ total, 9 per condition)

With regard to potential usage of desk fans, a statistically significant difference was observed. Considering the three thermal conditions as a whole, a Wilcoxon SignedRanks Test indicated that, when messaging was delivered, more participants said they would turn off desk fans $(z=-2.836, N-$ Ties $=11, p=0.005$, two-tailed $)$. Furthermore, a significant difference was also observed at each of the thermal conditions $27^{\circ} \mathrm{C}(\mathrm{z}=$ -2.032, $\mathrm{N}-$ Ties $=5, \mathrm{p}=0.042$, two-tailed $)$ and $29.5^{\circ} \mathrm{C}(\mathrm{z}=-2.020, \mathrm{~N}-$ Ties $=6, \mathrm{p}=$ 0.043 , two-tailed). No difference was found at thermal condition $24.5^{\circ} \mathrm{C}$, all nine participants reporting that they would not use desk fans throughout the two hours, either without or with messaging.

\subsection{Messaging at first hour}

For this part of the study, the messaging was present from the outset for the participants, remained visible for the first hour, and was then removed from the participants at the second hour. The purpose was to test whether the order of presenting messaging affected responses (compared to appearance at second hour), and also whether there was any persistence of effect after its removal. Again, a perspective was sought across the same three summertime indoor temperature conditions (26 subjects in total, 8-9 participants per condition; missing one participant at $29.5^{\circ} \mathrm{C}$ condition).

When messaging was present at the outset and then removed at the second hour, no statistically significant difference was observed on thermal evaluations between these two hours in any of the thermal conditions examined, either in the paired $T$ tests for thermal sensation or in the Wilcoxon Signed-Ranks tests for other thermal evaluations. 
However, thermal evaluations did appear slightly improved after messaging was removed.

Comparison between the second experiment (messaging appearing at second hour) and the third experiment (present at first hour) showed a less notable improvement for the presence of messaging as opposed to the appearance of messaging. Figures 12 and 13 show this comparison at $29.5^{\circ} \mathrm{C}$ for 'thermal comfort' and 'acceptability' evaluations, respectively. Regarding responses in relation to intended desk fan usage, no statistically-significant differences were observed by Wilcoxon Signed-Ranks Test, the pattern of reported intended usage being generally consistent with that of thermal preference.

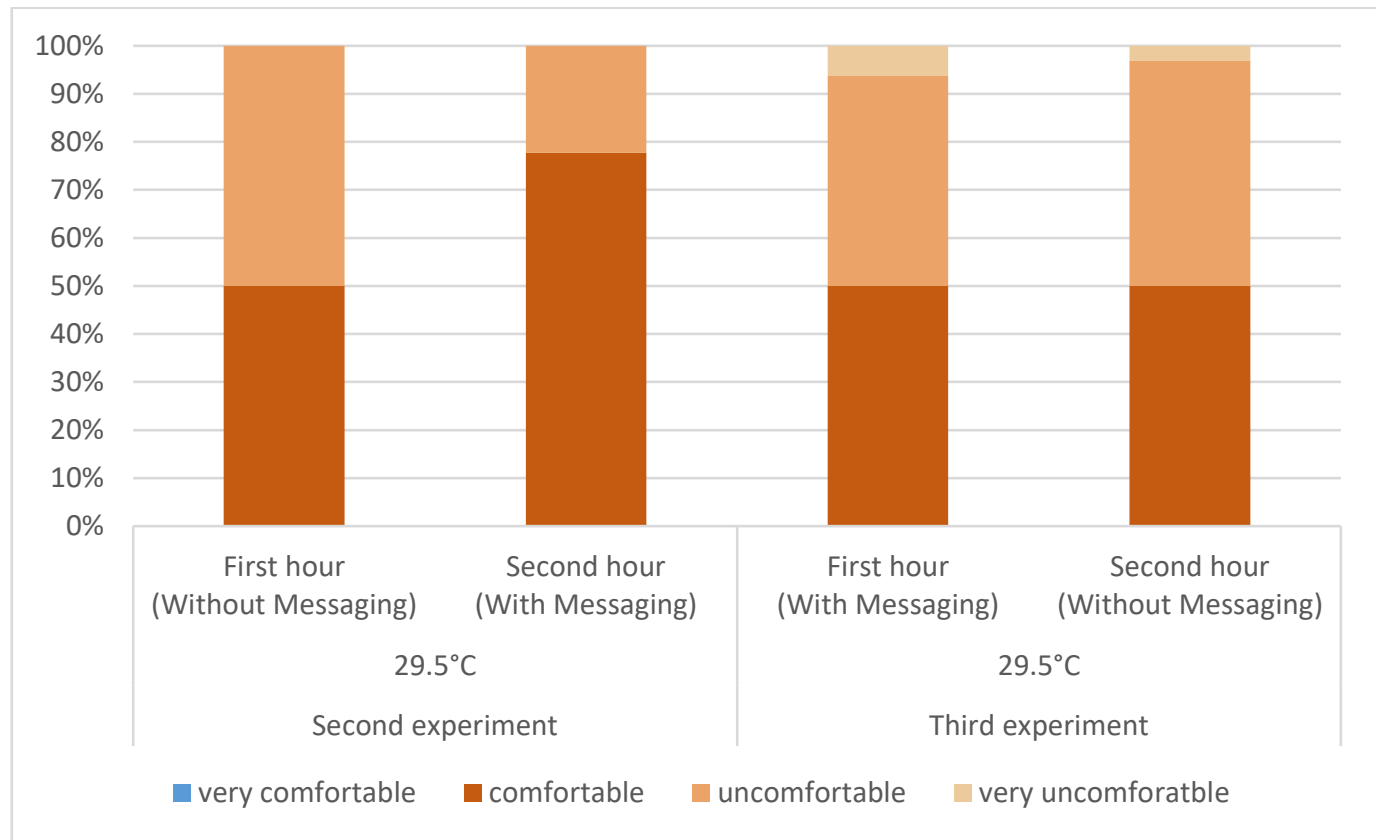

Figure 12 The comparison of votes for thermal comfort at $29.5^{\circ} \mathrm{C}$ (with/without messaging)

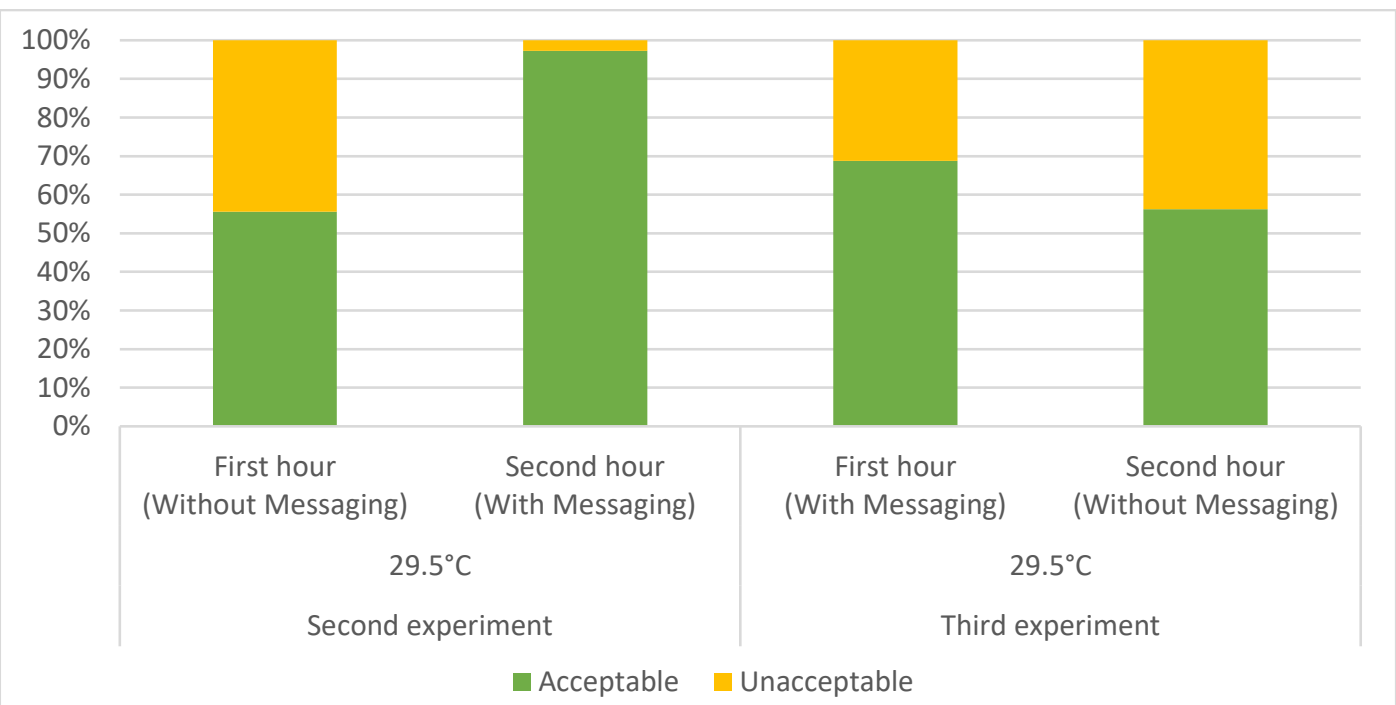

Figure 13 The comparison of votes for thermal acceptability at $29.5^{\circ} \mathrm{C}$ (with/without messaging) 
In addition, cross-session group comparisons (i.e. comparisons between the situations without messaging in the second and third experiments, and comparisons between the situations with messaging in the second and third experiments) also showed no statistically significant differences.

\subsection{Effective 'control group' comparison}

The preceding results arise from statistical comparisons between individual participants across the first and second hours of a test session, to show whether the appearance, or presence, of messaging affected subjective responses, over a range of summertime office temperatures. The experimental design adopted also allowed for, in effect, a 'control group' comparison, where the subjective responses of participants who were not being exposed to messaging in the first hour could be compared to responses of participants who were being exposed to messaging in the first hour (data utilised was only for those periods when participants were in thermal equilibrium). This was conducted, and statistical analysis showed no significant difference between the two groups.

\section{Discussion}

\subsection{Effects on thermal evaluations}

Messaging in the form of (artificial) energy feedback and social normative information were applied across a range indoor summertime temperatures in a multi-occupant office setting. For the sample size utilised, a statistically-significant effect on reported thermal sensations was observed at the $29.5^{\circ} \mathrm{C}$ condition after messaging appeared at the second hour of the session, being lower (cooler) than those of the first hour when no messaging was present. No significant differences were observed at $27^{\circ} \mathrm{C}$ and $24.5^{\circ} \mathrm{C}$ conditions. Reported thermal comfort was also improved after the appearance of messaging at the second hour, significant at the $95 \%$ level, when analysing the conditions $29.5^{\circ} \mathrm{C}$ and $27^{\circ} \mathrm{C}$ in aggregate. Thermal acceptability, preference, satisfaction and tolerance showed no statistically-significant differences, though some improvements were still observed. When the order was reversed, and messaging was present at the first hour and then removed at the second hour, no significant differences were observed between these hours at any of the thermal conditions (though some evaluations appeared slightly improved after the removal of messaging).

This suggests that it is the appearance of messaging that is affecting responses, and not so much its presence and then removal (though removal does have a slight effect, too). These effects are observed at the higher temperatures of the range, and not at the near-neutral condition of $24.5^{\circ} \mathrm{C}$; could this be because it is difficult to 'improve' upon the sensation of neutrality?

It is not possible to make any comment in relation to the existing social beliefs of the participants (Deuble and De dear, 2012), since all could be considered as positively 
disposed towards energy and environment. Thermal comfort is a prominent factor in influencing people's energy-using attitude, and thus energy-saving information campaigns could potentially affect a person's need of thermal comfort (Heijs and Stringer, 1988). Thermal comfort is a subjective evaluation about the thermal environment being experienced by a person; it is not only influenced by the physical environment and personal parameters, but also is affected through psychological mechanisms. Feedback messaging in this study motivated participants to accept their thermal conditions by interacting with their energy-use information. This information in the form of energy feedback and social normative data could potentially influence participants' minds and cause them to think about "how exactly uncomfortable am I?" and "how much can I tolerate this thermal environment?". Although participants had no means to control their thermal environment in this case, this study nevertheless has shown that feedback messaging can affect human thermal evaluation, and forms an important starting point for further investigations.

\subsection{Effects on intended behaviour}

No significant differences were observed regarding intention to use cooling devices. However, there were significant differences shown, as a whole, at $29.5^{\circ} \mathrm{C}$ and $27^{\circ} \mathrm{C}$ thermal conditions, with respect to intended desk fan usage, after the appearance of messaging, with more participants stating that they would turn off desk fans.

Since the behaviours of using heating/cooling devices are normally the result of a series of processes, generally including external (building and building-equipment properties, physical environment, and temporal) and internal (biological, psychological, and social) factors (Yan et al., 2017), there would potentially be a psychological element in occupants deciding how they would use their personal conditioning systems in offices.

It is natural that if people want to be cooler, then the next step is to become cooler by controlling cooling devices, if such devices are available. However, the messaging in this study was apparently able to weaken the link between preference and intended behaviour. At $29.5^{\circ} \mathrm{C}$ of the second experiment (appearance of messaging at second hour), the messaging had no effect on the preference to be cooler (Figure 10), but did reduce the intention to use cooling devices (Figure 11). Similarly, the intended usage of desk fans showed the same results. This was especially noticeable at $29.5^{\circ} \mathrm{C}$, possibly because participants in the uncomfortable conditions might be more inclined to think about using their personal comfort system, with preference no longer being a main driver of behaviour associated with control of their microclimate.

\subsection{Messaging, adaptation and health}

Thermal sensation is both a sensory experience and a psychological phenomenon (Parsons, 2014). Although many studies present the thermoreceptor theory to explain how people feel warmth and coldness, people might be less sensitive to the sensory 
inputs when conditions are near-comfort (non-extreme), and more sensitive to other influences, such as messaging, especially for the sedentary activities in office buildings. Consequently, if messaging is able to impact the process of personal thermal evaluation, then it may also be able to influence personal behaviours, including actual usage of personal comfort systems, which could lead to energy-saving behaviours.

Psychological adaptation is already known to be one of the three main modes of adaptation, alongside behavioural and physiological (Nicol et al., 2012). The work reported here presents evidence of the link between 'condition of mind' and thermal sensation, as mediated by messaging in the form of energy feedback and social norm information. Such messaging could now be seen in the context of a further adaptive opportunity when delivered in combination with the means to make adjustments to one's personal environment, for example via personal desk-based comfort systems. However, the messaging delivered in the form investigated here would be under the control of the building operator, and not the occupant, the occupant responding subconsciously to the messaging. If further research with larger sample sizes confirms the effects observed, then it is essential that, prior to any potential future application, careful consideration is given to all aspects, particularly to avoid the possibility of adverse human health and well-being effects. For example, perceiving warm conditions as acceptable may be undesirable on health and well-being grounds. The length of time for which such subjective evaluations persist following appearance of messaging would be useful knowledge in this respect. It was not possible from our study to clearly determine this period. These are essential for assessing the potential and desirability for future application in practice.

\subsection{Limitations, uncertainty and future work}

The aim of this study was to observe whether messaging affected thermal evaluations over a range of summertime office temperatures, and to use the outcome to design a more focussed future investigation. Whilst effects were indeed observed for the size of sample employed, their statistical significance was at the $95 \%$ confidence level. This suggests that while effects may well be present, we recommend that a larger study be conducted.

The fact that this was a controlled room-based study meant that the experimental nature of the testing could not be disguised to participants. However, the actual purpose of the experiments (the effects of messaging) were not discussed with participants prior to their tests, and messaging was encountered for the first time by each participant on their work station computer screen during their test session. Nevertheless, the possibility that some degree of 'observer effect' might have been present cannot be completely ruled out, though we consider this unlikely given that messaging also had no, or even adverse, effects on subjective evaluations in a number of cases. Furthermore, the use of a controlled room could be considered as a somewhat 'virtual' situation. However, this was considered necessary for this first 
investigation into this area so as to isolate the effect of messaging through the minimisation of other confounding factors. Questions concerning imaginary access to a cooling device or desk fan will provide a useful point of comparison when actual access is provided in our next planned set of experiments.

Uncertainty is involved in subjective data about thermal comfort and other thermal evaluations. Shipworth et al. (2016) pointed out the diversity observed in thermal comfort votes and explained such a diversity by a theoretical model with multiple drivers, including contextual and human drivers. To reduce these uncertainties, this study controlled the contextual factors and maintained participants' physiological status to be as stable as possible. Furthermore, our study minimised the influence of the inter-personal differences, such as individual thermal preferences and experiences (Shipworth et al., 2016), through within-subject comparisons. Nevertheless, uncertainties would still have been present, but this is common to all subjective thermal comfort studies. Our future work will focus on the application problem - whether messaging has any impact on the actual usage of personal comfort systems in the office context.

\section{Conclusions}

From the principles of adaptation, psychological processes are known to influence human thermal comfort evaluation, but can these processes be 'managed' in some way? This paper is the first to show that suitably-designed messaging can do this. There is also potential to influence energy consumption. Implementation of messaging in multi-occupant offices, combined with personal comfort devices, may offer an important contribution to addressing the growing international challenge of reducing cooling energy demand while maintaining thermal comfort.

The effect on subjective evaluations of messaging in the form of energy feedback and social normative information was investigated with a sample of human participants in a controlled environment room, set up as a multi-occupant office. Investigations were conducted across a range of warm office conditions $\left(24.5^{\circ} \mathrm{C}, 27^{\circ} \mathrm{C}, 29.5^{\circ} \mathrm{C}\right.$, as might be encountered in summertime). Experimental sessions of two hours' duration were undertaken for: no messaging; messaging appearing at the second hour; messaging present at first hour then removed at second hour. For the participant sample tested, findings are as follows.

1. Appearance of messaging had a statistically significant effect on reported thermal sensations and thermal comfort at the higher end of the temperature range employed, but had no significant effect on other subjective evaluations.

2. Appearance of messaging affected reported intended desk fan usage, again at the higher temperatures.

3. Presence, then removal, of messaging showed no significant effects, as did an effective control group comparison. 
4. Whilst effects were observed, these were significant at the $95 \%$ confidence level, and it is recommended that a larger scale study be undertaken to confirm, or otherwise, these observations.

The envisaged context for the work has been multi-occupant offices with individual work locations each equipped with a personal comfort system, and this study has served to identify those thermal conditions where effects of messaging may be present. This knowledge is now being utilised to design a more focussed, larger-scale investigation for the personal comfort system context. Of particular interest will be effects on actual usage of energy-consuming thermal comfort devices.

The method described in this paper can be used for future controlled studies in this field. In particular, we would recommend that a thorough investigation of the effects of such messaging on subjective thermal evaluations, appliance usage and energy efficiency, inclusive of potential health and well-being implications, be conducted prior to any future possible deployment.

\section{Acknowledgements}

The authors gratefully acknowledge the contributions and support by laboratory technical staff in the School of Architecture, Building and Civil Engineering, Loughborough University, UK during the design and implementation of the experimental work in the School's climate chamber. Z. Li also expresses gratitude for the financial support afforded by a doctoral scholarship from Loughborough University, UK.

\section{References}

Arens, E., Zhang, H., \& Huizenga, C. (2006). Partial-and whole-body thermal sensation and comfortPart I: Uniform environmental conditions. Journal of thermal Biology, 31(1-2), 53-59.

ASHRAE 55-2013. (2013). Thermal environment conditions for human occupancy.

Balaji, B., Teraoka, H., Gupta, R., \& Agarwal, Y. (2013, November). Zonepac: Zonal power estimation and control via hvac metering and occupant feedback. In Proceedings of the 5th ACM Workshop on Embedded Systems For Energy-Efficient Buildings (pp. 1-8). ACM.

Bordass, W., Leaman, A., \& Willis, S. (1994, May). Control strategies for building services: the role of the user. In Chartered Institute of Building Conference on Buildings and the Environment, Building Research Establishment, UK.

Brager, G. S., \& De Dear, R. J. (1998). Thermal adaptation in the built environment: a literature review. Energy and buildings, 27(1), 83-96.

Brager, G., Paliaga, G., \& De Dear, R. (2004). Operable windows, personal control and occupant comfort. Center for the Built Environment. 
Carrico, A. R., \& Riemer, M. (2011). Motivating energy conservation in the workplace: An evaluation of the use of group-level feedback and peer education. Journal of environmental psychology, 31(1), 1 13.

Cialdini, R. B., Reno, R. R., \& Kallgren, C. A. (1990). A focus theory of normative conduct: Recycling the concept of norms to reduce littering in public places. Journal of personality and social psychology, 58(6), 1015.

Clausen, G., \& Wyon, D. P. (2008). The combined effects of many different indoor environmental factors on acceptability and office work performance. HVAC\&R Research, 14(1), 103-113.

Croome, D. J., Gan, G., \& Awbi, H. B. (1992). Evaluation of thermal comfort and indoor air quality in offices: Thermal models based on laboratory tests at steady state conditions cannot accurately predict the real thermal environment where the conditions are transient and where occupants change their activities. Building research and information, 20(4), 211-225.

Dantsiou, D. and Sunikka-Blank, M. (2015). Why does energy use feedback not work in workplaces? Insights from social practice theory. ECEEE 2015 Summer Study - First Fuel now, Toulon, France, 2227-2236

De Dear, R. J., Brager, G. S., Reardon, J., \& Nicol, F. (1998). Developing an adaptive model of thermal comfort and preference/discussion. ASHRAE transactions, 104, 145.

De Dear, R. J., Leow, K. G., \& Foo, S. C. (1991). Thermal comfort in the humid tropics: Field experiments in air conditioned and naturally ventilated buildings in Singapore. International Journal of Biometeorology, 34(4), 259-265.

Delmas, M. A., Fischlein, M., \& Asensio, O. I. (2013). Information strategies and energy conservation behavior: A meta-analysis of experimental studies from 1975 to 2012. Energy Policy, 61, 729-739.

Deuble, M. P., \& de Dear, R. J. (2012). Green occupants for green buildings: the missing link?. Building and Environment, 56, 21-27.

Dolan, P., \& Metcalfe, R. D. (2015). Neighbors, knowledge, and nuggets: two natural field experiments on the role of incentives on energy conservation.

Ehrhardt-Martinez, K., Donnelly, K. A., \& Laitner, S. (2010, June). Advanced metering initiatives and residential feedback programs: a meta-review for household electricity-saving opportunities. Washington, DC: American Council for an Energy-Efficient Economy.

Erickson, V. L., Lin, Y., Kamthe, A., Brahme, R., Surana, A., Cerpa, A. E., ... \& Narayanan, S. (2009, November). Energy efficient building environment control strategies using real-time occupancy measurements. In Proceedings of the First ACM Workshop on Embedded Sensing Systems for Energy-Efficiency in Buildings (pp. 19-24). ACM.

Fanger, P. O. (1970). Thermal comfort. Analysis and applications in environmental engineering. Thermal comfort. Analysis and applications in environmental engineering.

Feldmeier, M., \& Paradiso, J. A. (2010, November). Personalized HVAC control system. In Internet of Things (IOT), 2010 (pp. 1-8). IEEE.

Fischer, C. (2008). Feedback on household electricity consumption: a tool for saving energy?. Energy efficiency, 1(1), 79-104. 
Foster, D., Lawson, S., Blythe, M., \& Cairns, P. (2010, October). Wattsup?: motivating reductions in domestic energy consumption using social networks. In Proceedings of the 6th Nordic Conference on Human-Computer Interaction: Extending Boundaries (pp. 178-187). ACM.

Gans, W., Alberini, A., \& Longo, A. (2013). Smart meter devices and the effect of feedback on residential electricity consumption: Evidence from a natural experiment in Northern Ireland. Energy Economics, 36, 729-743.

Goldstein, N. J., Martin, S. J., \& Cialdini, R. (2008). Yes!: 50 scientifically proven ways to be persuasive. Simon and Schuster.

Gulbinas, R., \& Taylor, J. E. (2014). Effects of real-time eco-feedback and organizational network dynamics on energy efficient behavior in commercial buildings. Energy and buildings, 84, 493-500.

Handgraaf, M. J., de Jeude, M. A. V. L., \& Appelt, K. C. (2013). Public praise vs. private pay: Effects of rewards on energy conservation in the workplace. Ecological Economics, 86, 86-92.

Hang-yat, L. A., \& Wang, D. (2013, November). Carrying my environment with me: A participatorysensing approach to enhance thermal comfort. In Proceedings of the 5th ACM Workshop on Embedded Systems For Energy-Efficient Buildings (pp. 1-8). ACM.

Hedge, A. (1982). The open-plan office: A systematic investigation of employee reactions to their work environment. Environment and Behavior, 14(5), 519-542.

Heijs, W. I. M., \& Stringer, P. (1988). Research on residential thermal comfort: some contributions from environmental psychology. Journal of environmental psychology, 8(3), 235-247.

Houde, S., Todd, A., Sudarshan, A., Flora, J. A., \& Armel, K. C. (2013). Real-time feedback and electricity consumption: A field experiment assessing the potential for savings and persistence. The Energy Journal, 34(1), 87.

Hoyt, T., Schiavon, S., Piccioli, A., Cheung, T., Moon, D., \& Steinfeld, K. (2017). CBE Thermal Comfort Tool Center for the Built Environment. University California Berkeley, http://comfort. cbe. berkeley. edu.

Huizenga, C., Zhang, H., Arens, E., \& Wang, D. (2004). Skin and core temperature response to partial-and whole-body heating and cooling. Journal of Thermal Biology, 29(7), 549-558.

Jain, R. K., Taylor, J. E., \& Culligan, P. J. (2013). Investigating the impact eco-feedback information representation has on building occupant energy consumption behavior and savings. Energy and Buildings, 64, 408-414.

Karjalainen, S., \& Koistinen, O. (2007). User problems with individual temperature control in offices. Building and Environment, 42(8), 2880-2887.

Lam, A. H. Y., Yuan, Y., \& Wang, D. (2014, June). An occupant-participatory approach for thermal comfort enhancement and energy conservation in buildings. In Proceedings of the 5th international conference on Future energy systems (pp. 133-143). ACM.

Lee, S. Y., \& Brand, J. L. (2010). Can personal control over the physical environment ease distractions in office workplaces?. Ergonomics, 53(3), 324-335.

Loveday, D. L., Parsons, K. C., Taki, A. H., \& Hodder, S. G. (2002). Displacement ventilation environments with chilled ceilings: thermal comfort design within the context of the BS EN ISO7730 versus adaptive debate. Energy and Buildings, 34(6), 573-579. 
Luo, M., Cao, B., Zhou, X., Li, M., Zhang, J., Ouyang, Q., \& Zhu, Y. (2014). Can personal control influence human thermal comfort? A field study in residential buildings in China in winter. Energy and Buildings, 72, 411-418.

Martin, S., \& Rivers, N. (2015). Information provision, market incentives, and household electricity consumption: Evidence from a large-scale field trial.

Martinez, D., Fiala, D., Cook, M. J., \& Lomas, K. J. (2000). Predicted comfort envelopes for office buildings with passive downdraught evaporative cooling. In Proceeding ROOMVENT 2000 Conference (Vol. 1, pp. 53-8).

Matthies, E. (2005). Wie koennen PsychologInnen ihr Wissen besser an den/die Praktikerln bringen? Vorschlag eines neuen integrativen Einflussschemas umweltgerechten Alltagshandelns/How can psychologists better put across their knowledge to practioners? Suggesting a new, integrative influence model of pro-environmental everyday behaviour. Umweltpsychologie, 9(1).

Nicol, F., Humphreys, M., \& Roaf, S. (2012). Adaptive thermal comfort: principles and practice. Routledge.

Oseland, N. A. (1995). Predicted and reported thermal sensation in climate chambers, offices and homes. Energy and Buildings, 23(2), 105-115.

Parsons, K. (2014). Human thermal environments: the effects of hot, moderate, and cold environments on human health, comfort, and performance. CRC press.

Parsons, K. C. (2002). The effects of gender, acclimation state, the opportunity to adjust clothing and physical disability on requirements for thermal comfort. Energy and Buildings, 34(6), 593-599.

Peschiera, G., Taylor, J. E., \& Siegel, J. A. (2010). Response-relapse patterns of building occupant electricity consumption following exposure to personal, contextualized and occupant peer network utilization data. Energy and Buildings, 42(8), 1329-1336.

Petersen, J. E., Shunturov, V., Janda, K., Platt, G., \& Weinberger, K. (2007). Dormitory residents reduce electricity consumption when exposed to real-time visual feedback and incentives. International Journal of Sustainability in Higher Education, 8(1), 16-33.

Rohles Jr, F. H. (2007). Temperature \& Temperment: A Psychologist Looks at Comfort. Ashrae Journal, 49(2), 14.

Schleich, J., Klobasa, M., Gölz, S., \& Brunner, M. (2013). Effects of feedback on residential electricity demand-Findings from a field trial in Austria. Energy Policy, 61, 1097-1106.

Schweiker, M., \& Shukuya, M. (2009). Comparison of theoretical and statistical models of airconditioning-unit usage behaviour in a residential setting under Japanese climatic conditions. Building and Environment, 44(10), 2137-2149.

Schweiker, M., \& Wagner, A. (2016). The effect of occupancy on perceived control, neutral temperature, and behavioral patterns. Energy and Buildings, 117, 246-259.

Shahzad, S., Calautit, J. K., Aquino, A. I., Nasir, D. S., \& Hughes, B. R. (2017). A user-controlled thermal chair for an open plan workplace: CFD and field studies of thermal comfort performance. Applied Energy, 207, 283-293.

Shahzad, S., Calautit, J. K., Calautit, K., Hughes, B., \& Aquino, A. I. (2018). Advanced personal comfort system (APCS) for the workplace: A review and case study. Energy and Buildings, 173, 689709. 
Shipworth, D., Huebner, G., Schweiker, M., \& Kingma, B. (2016). Diversity in Thermal Sensation: drivers of variance and methodological artefacts. In Proceedings of 9th Windsor conference: Making comfort relevant (Vol. 9, pp. 56-72). Network for Comfort and Energy Use in Buildings (NCEUB).

Staddon, S. C., Cycil, C., Goulden, M., Leygue, C., \& Spence, A. (2016). Intervening to change behaviour and save energy in the workplace: A systematic review of available evidence. Energy Research \& Social Science, 17, 30-51.

Stone, N. J. (2001). Designing effective study environments. Journal of environmental psychology, 21(2), 179-190.

Taufik, D., Bolderdijk, J. W., \& Steg, L. (2015). Acting green elicits a literal warm glow. Nature Climate Change, 5(1), 37-40.

Toftum, J., Thorseth, A., Markvart, J., \& Logadóttir, Á. (2018). Occupant response to different correlated colour temperatures of white LED lighting. Building and Environment, 143, 258-268.

Trinh, K. (2015, October). A Demonstration of an Energy Feedback Research Platform in a Field Study of Real-Time Social Comparisons. In Behavior, Energy and Climate Change Confererence: 2015 Conference Proceedings.

Vasiljevic, M., Pechey, R., \& Marteau, T. M. (2015). Making food labels social: The impact of colour of nutritional labels and injunctive norms on perceptions and choice of snack foods. Appetite, 91, 56-63.

Vellei, M., Natarajan, S., Biri, B., Padget, J., \& Walker, I. (2016). The effect of real-time context-aware feedback on occupants' heating behaviour and thermal adaptation. Energy and Buildings, 123, 179191.

Yan, D., Hong, T., Dong, B., Mahdavi, A., D’Oca, S., Gaetani, I., \& Feng, X. (2017). IEA EBC Annex 66: Definition and simulation of occupant behavior in buildings. Energy and Buildings, 156, 258-270.

Yao, R., Li, B., \& Liu, J. (2009). A theoretical adaptive model of thermal comfort-Adaptive Predicted Mean Vote (aPMV). Building and environment, 44(10), 2089-2096.

Yao, Y., Lian, Z., Liu, W., \& Shen, Q. (2007). Experimental study on skin temperature and thermal comfort of the human body in a recumbent posture under uniform thermal environments. Indoor and Built Environment, 16(6), 505-518.

Zhang, H., Arens, E., \& Zhai, Y. (2015). A review of the corrective power of personal comfort systems in non-neutral ambient environments. Building and Environment, 91, 15-41.

Zhong, C. B., \& Leonardelli, G. J. (2008). Cold and lonely does social exclusion literally feel cold?. Psychological Science, 19(9), 838-842. 
Appendix A Background Questionnaire 


\section{Background Questionnaire}

This questionnaire is only used for this research. All information that is collected from your replies to this questionnaire will be kept strictly confidential. Collection, storage and usage of data will comply with GDPR.

${ }^{*}$ Required

1. Email address *

2. Gender *

Mark only one oval

Female

Male

3. Nationality *

4. Height $(\mathrm{cm})$ *

5. Weight $(\mathbf{K g})$ *

6. Age *

7. 1. How long have you been in the UK? *

Mark only one oval

Less than 1 year

1 to 3 years

More than 3 years

8. 2. Are you a...? *

Mark only one oval

Student

Research Staff

Academic Staff

Administration Staff

Other: 
9. 3. Do you spend majority of your time in an office? *

Mark only one oval.

$\longrightarrow$ Yes Skip to question 9 .

No skip to question 10

10. If yes, What kind of office do you work in? *

Mark only one oval

$\bigcirc$ Open-plan office

Cellular office

Office shared by small groups of people

Other:

11. 4. How long do you spend in your office on a typical day? * Mark only one oval.
$0-2$ hours
2-4 hours
4-6 hours
$6-8$ hours
over 8 hours

Now, imagine you are in an office shared with your colleagues:

12. 5. How many of your office colleagues do you think would adjust heating or cooling thermostats to reduce energy consumption? *

Mark only one oval
None
Very Few
$25 \%$
$50 \%$
$75 \%$
Almost All

13. 6. What would you think, if your office colleagues let your office condition become too cold in summer or too warm in winter? *

Mark only one oval.

Strongly disapprove

Disapprove

Neither approve nor disapprove

Approve

Strongly approve 
14. 7. By changing our heating/cooling use behaviour, office workers like me can reduce energy consumption in offices. *

Mark only one oval.
Strongly disagree
Disagree
Neither disagree nor agree
Agree
Strongly Agree

15. 8. I would like to reduce the amount of heating/cooling energy that I personally use. * Mark only one oval.

Strongly disagree
Disagree
Neither disagree nor agree
Agree
Strongly Agree

16. 9. What is your favourite type of music? *
Tick all that apply
$\square$ Pop
Classical
Rock
Blues
Jazz
Folk
Hip pop
Other:

17. 10. I can listen to music while working, without distraction. *

Mark only one oval

$\longrightarrow$ Strongly disagree

Disagree

Neither disagree nor agree

Agree

Strongly Agree

18. 11. Playing background music in the office does not disturb colleagues. *

Mark only one ova

Strongly disagree

Disagree

Neither disagree nor agree

Agree

Strongly Agree 
Appendix B In-session questionnaire

\section{In-test Questionnaire}

*Required

1. Your reference number *

2. Your position (based on picture below): *

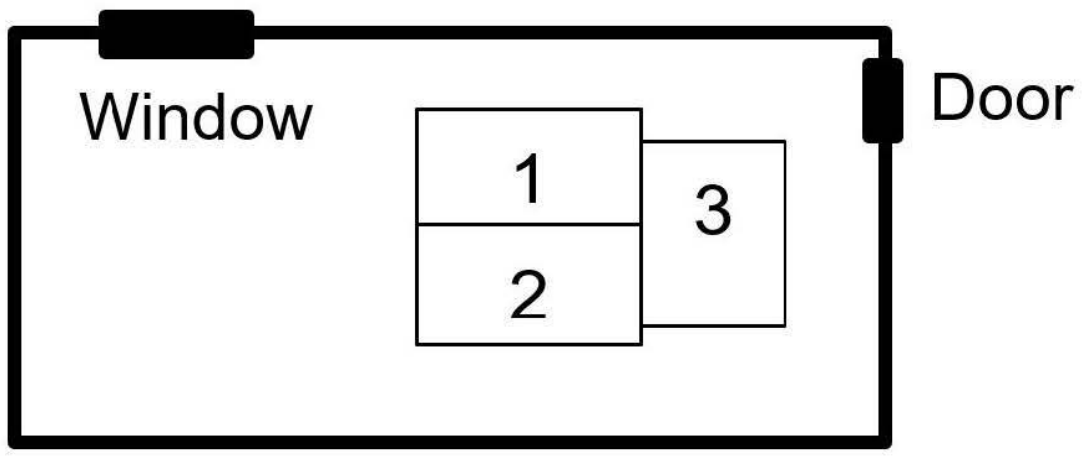

Mark only one oval.

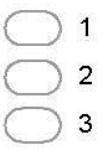

3. Time (Showing on display screen) (HH:MM) *

Example: 8.30 a.m.

Whole-body thermal evaluation

Please mark at any position on the scale that most agrees to your state. 
4. 1. Please indicate on the scale below how you feel thermally NOW. *

Mark only one oval

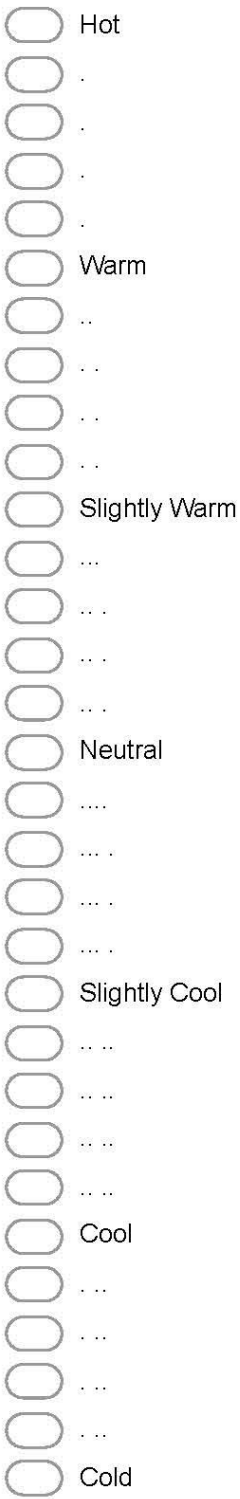

5. 2. Please rate your current level of thermal comfort * Mark only one oval

Very Comfortable

Comfortable

Uncomfortable

Very Uncomfortable 
6. 3. Please indicate how acceptable you find the thermal environment NOW *

Mark only one oval.

Acceptable

Unacceptable

7. 4. Please indicate on the scale how you would like to feel NOW *

Mark only one oval.

Cooler

No Change

Warmer

8. 5. Please indicate how satisfied you feel with the thermal environment NOW *

Mark only one oval.

Satisfied

Not Satisfied

9. 6. Do you find the current thermal environment tolerable? *

Mark only one oval.

Yes

No

10. 7. If you now had control of a cooling device that affected just yourself, how would you use it right now? *

Mark only one oval

Increase temperature (Here, this would use less energy)

Make no change (Here, this would use same energy)

Decrease temperature (Here, this would use more energy)

11. 8.If you had a small desk fan available, how would you use it right now?

Mark only one oval.

Turn it on (Here, this would use more energy)

Leave it turned off (Here, this would use same energy)

\section{Local-body thermal evaluation}

Please leave questions blank, if they are not applicable. 
12. 9. Please select the bocky area/s where you feel it uncomfortably warm. * Tick all that apply.
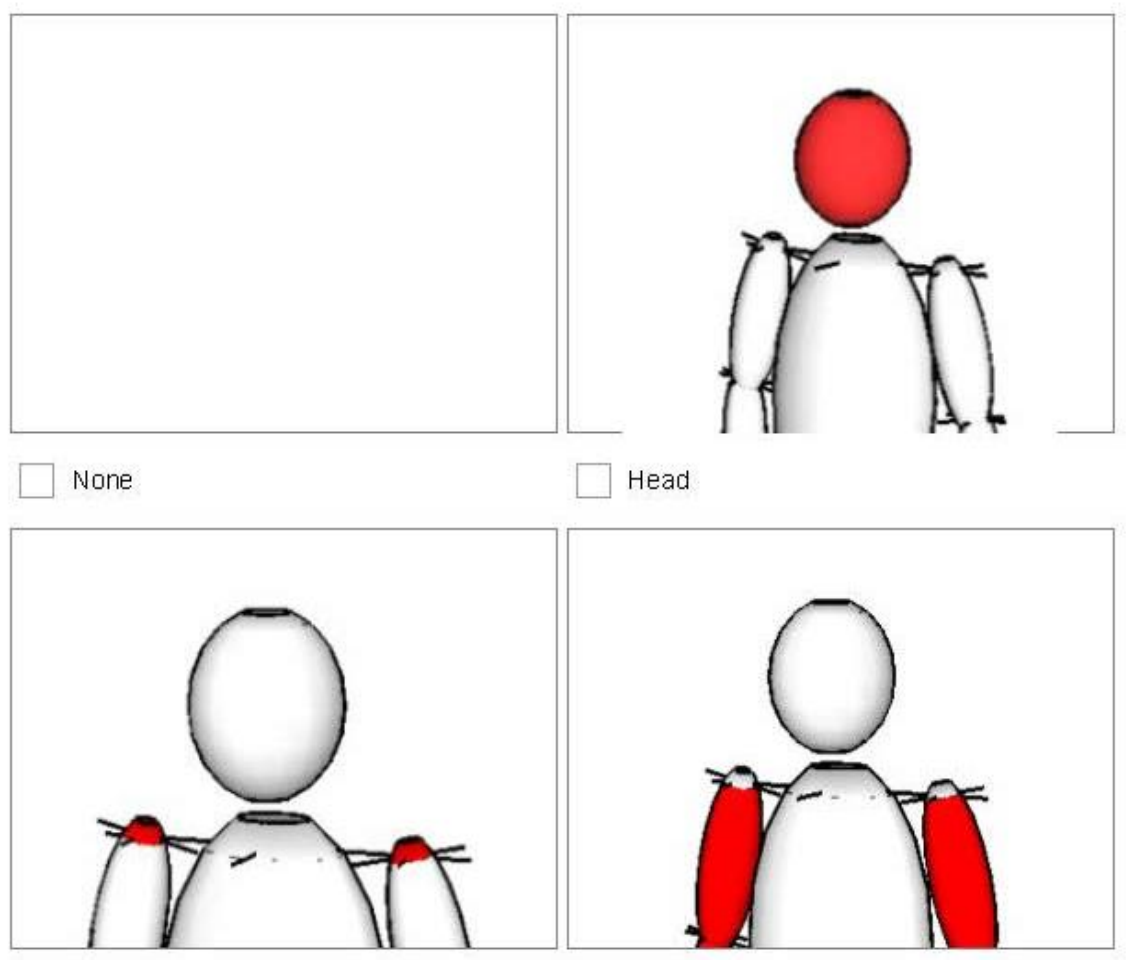

Shoulders

Ams
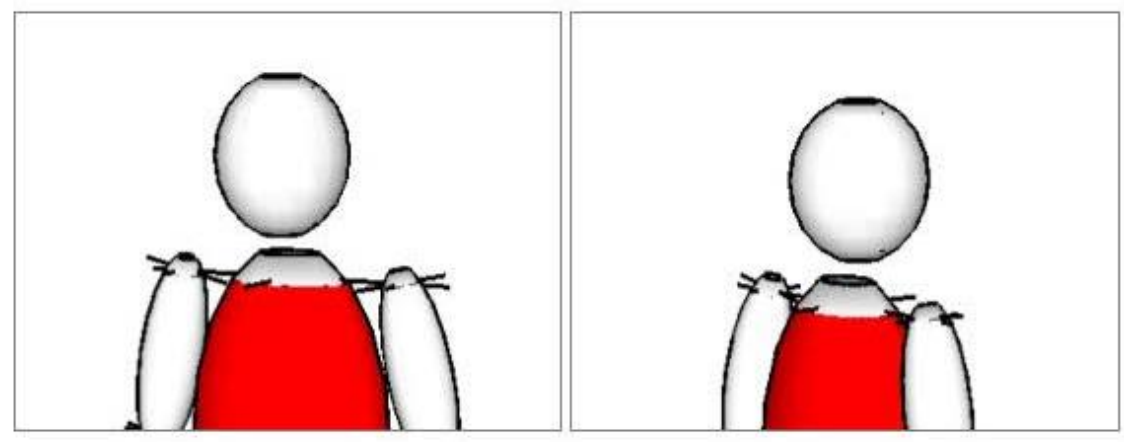

Torso

Back

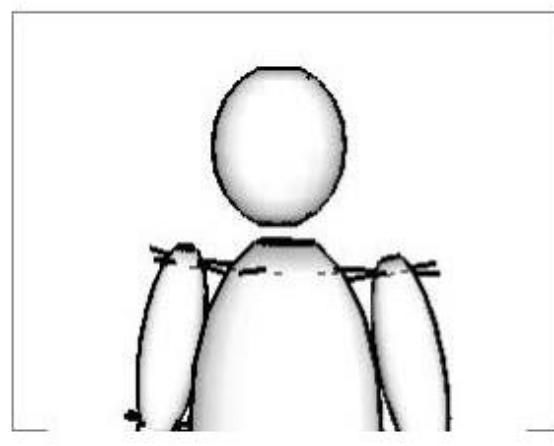

Lower body parts 
13. 10. Please select the bocty area/s where you feel it uncomfortably cool. * Tick all that apply.
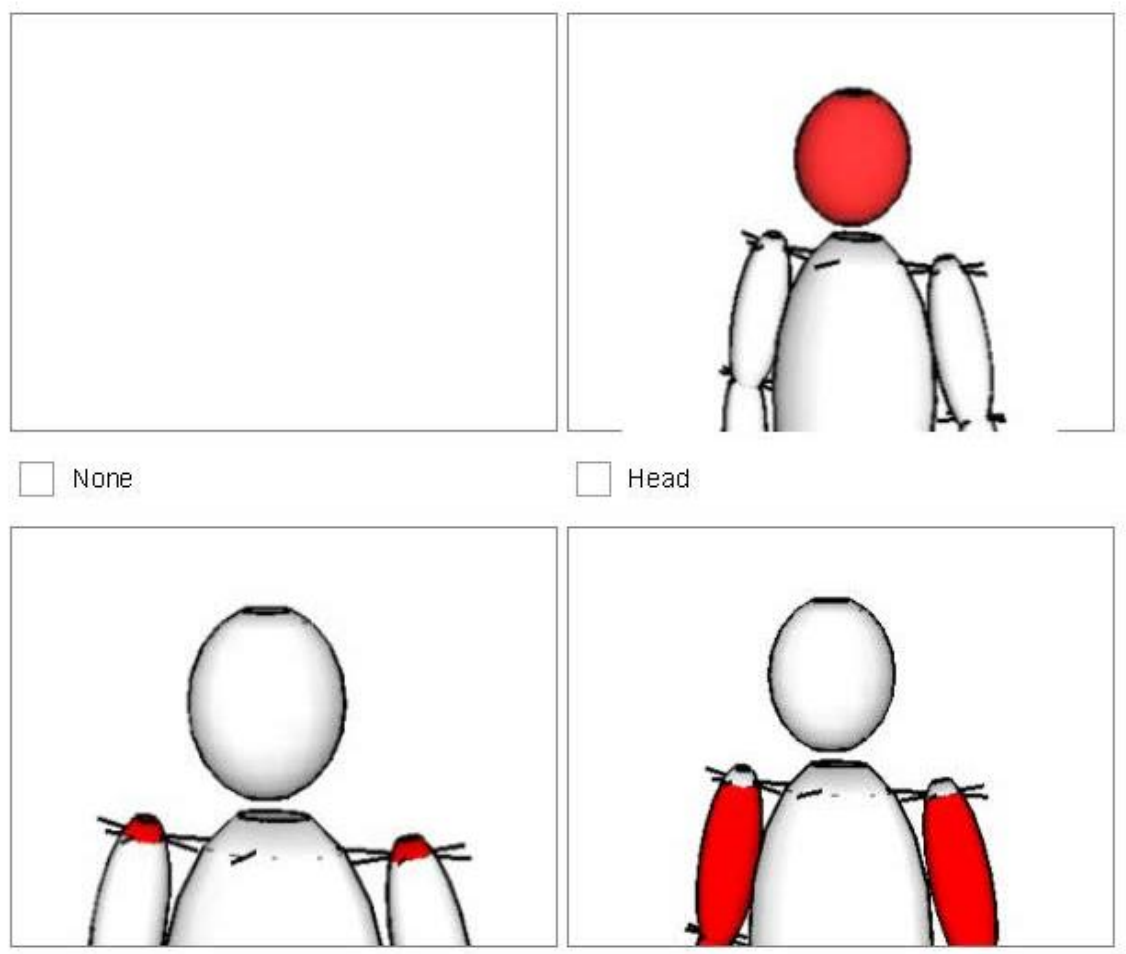

Shoulders

Ams
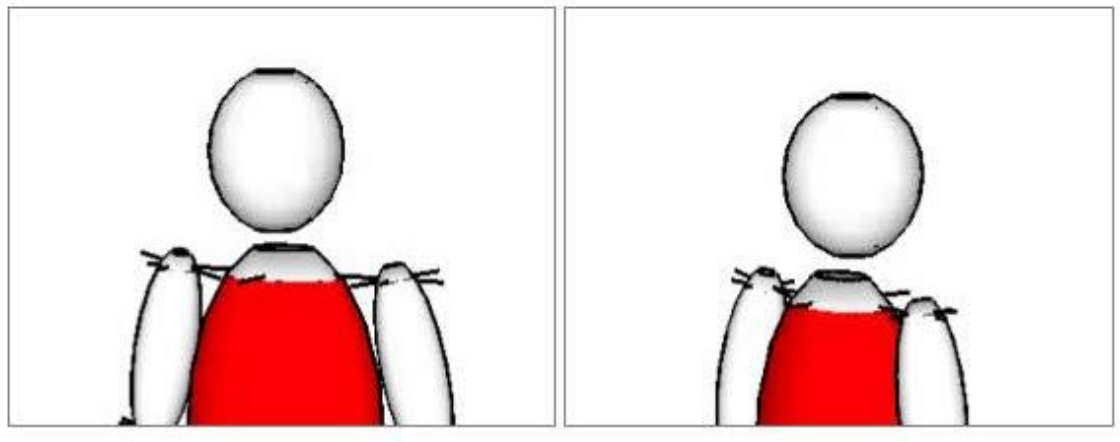

Torso

Back

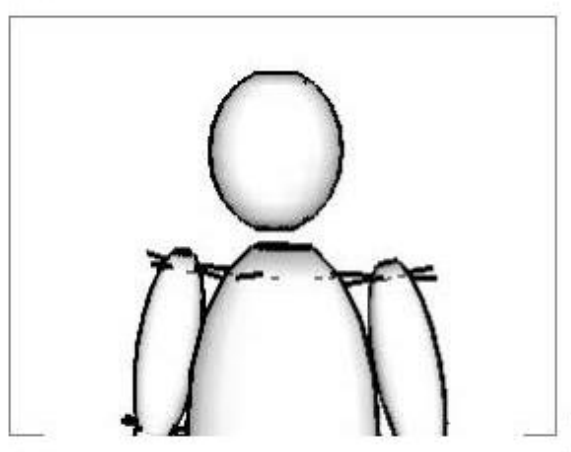

Lower body parts 
14. 11. Please select the bocty area/s where you feel air movement. *

Tick all that apply
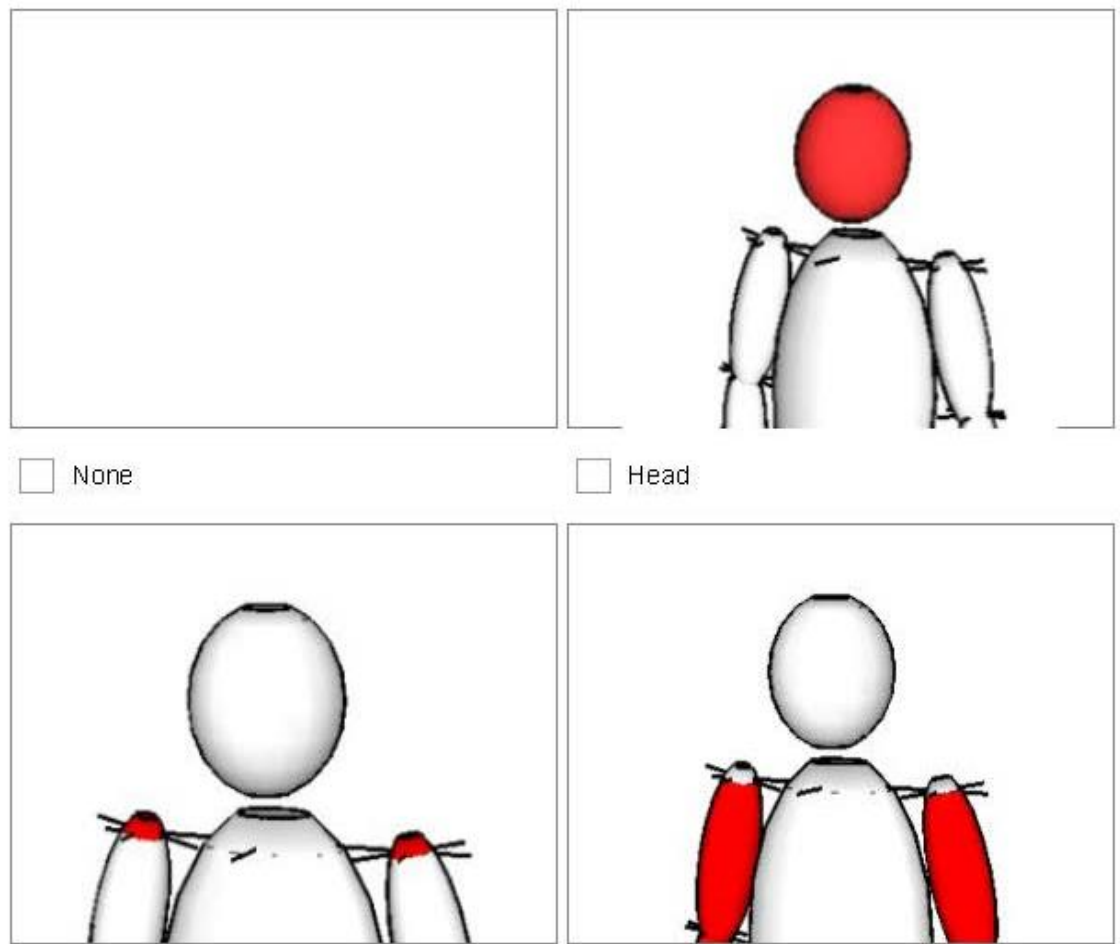

Shoulders

Ams

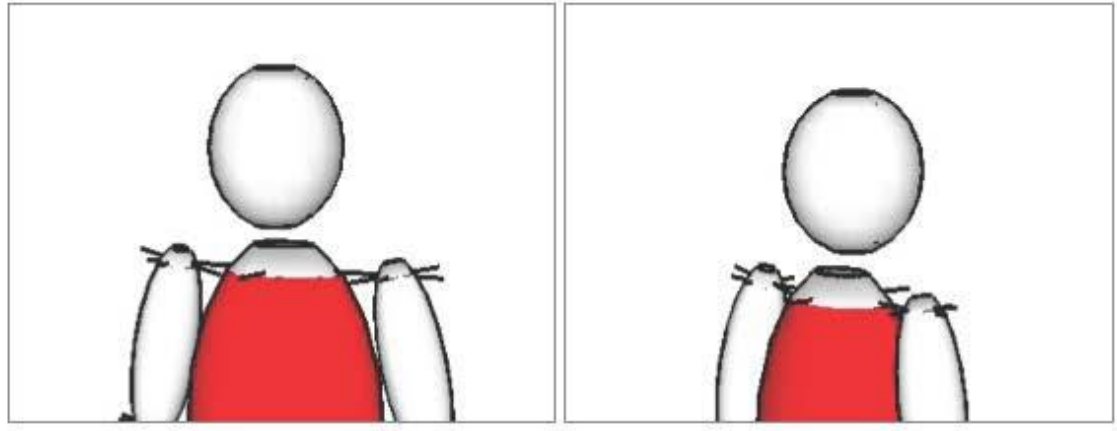

Torso

Back

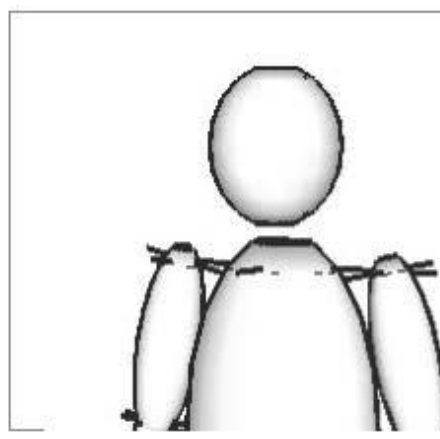

Lower body parts

15. Any further comment about your environment right now? 